\title{
Unintended reward costs: the effectiveness of customer referral reward programs for innovative products and services
}

\author{
David B. Dose ${ }^{1} \cdot$ Gianfranco Walsh $^{2} \cdot$ Sharon E. Beatty ${ }^{3} \cdot$ Ralf Elsner $^{4}$ \\ Received: 16 May 2017 / Accepted: 17 January 2019/Published online: 9 February 2019 \\ (C) The Author(s) 2019
}

\begin{abstract}
To encourage customers' referral behavior and expand their customer base, providers of innovative products and services often use customer referral reward programs (CRPs), though not all CRPs deliver on their initial promise. With one field experiment and four online experiments, this research investigates the effectiveness of rewarded referrals for recruiting new customers for more innovative (versus less innovative) offerings and outlines the conditions in which public referral rewards have unintended ramifications and decrease customers' referral likelihood. In addition to establishing these effects for more innovative offerings, this research identifies some moderating consequences, such that the detrimental effect of referral rewards on referral behavior can be attenuated by not disclosing referral rewards (for recommenders) to referral recipients, increasing the referral reward size, and rewarding both recommenders and referral recipients. These findings have theoretical and managerial implications.
\end{abstract}

Keywords Customer referral reward program $\cdot$ Innovative products and services $\cdot$ Reward scheme $\cdot$ Reward size $\cdot$ Reward visibility $\cdot$ Self-enhancement theory

Successfully launching innovations is important for a firm's long-term performance, yet new product failure rates range from $30 \%$ to more than $60 \%$ (Castellion and Markham 2013), suggesting the need for effective techniques to launch innovative products and services (e.g., Bass 1969; Kawakami and Parry 2013). Positive interpersonal communications, such as recommendations, should be beneficial (East et al. 2008), with many firms offering customer referral reward programs (CRPs) that grant financial incentives to existing customers making recommendations to potential new customers (Schmitt et al. 2011). Most CRPs are public in nature, with

Martin Mende served as Area Editor for this article.

Electronic supplementary material The online version of this article (https://doi.org/10.1007/s11747-019-00635-z) contains supplementary material, which is available to authorized users.

David B. Dose

d.dose@aston.ac.uk

Aston Business School, Birmingham B4 7ET, UK

Friedrich-Schiller-University Jena, Jena, Germany

University of Alabama, Tuscaloosa, AL 35487, USA

4 Rhenania BuchVersand Koblenz and Steinbeis-University Berlin, Berlin, Germany both parties aware of the reward. Bluesmart's CRP rewards existing customers $\$ 20$ for successful referrals of new customers for their innovative suitcases (Bluesmart Referral Program 2017), while emphasizing the public nature of their CRP. Commerzbank and Deutsche Bank (two German banks) operate 'public' CRPs in which the referral recipient provides the recommender's contact information and preferred reward when opening a bank account. Other firms (e.g., Pavlok) send automated emails to referral recipients to inform them of the CRP participation conditions and characteristics (e.g., reward size). Despite the prevalence of such CRPs, they may not be as effective as desired. As Intuit CEO, Scott Cook, stated: "We've tried various artificial stimulants to word of mouth, like financial incentives to recommenders. None have worked. Some produced isolated, but surprising, negative reaction" (Rosen 2009, p. 202). The potential for negative effects from reward-induced referrals is possible, but not fully understood (Wirtz et al. 2013).

A basic economic assumption is that incentives and customer motivations to refer or recommend to others are positively related (Ryu and Feick 2007), but we question this convention. Instead, for innovative offerings, public rewards even might diminish customer referrals. As a foundation for this surprising prediction, we draw on self-enhancement theory (e.g., Sedikides 1993) and posit that for more innovative 
(vs. less) offerings, public rewards undermine customers' motivation to refer, because this behavior largely reflects their desire to self-enhance or gain social approval (De Angelis et al. 2012). Granting referring customers a public reward undermines this satisfaction and reduces referral likelihood, consistent with behavioral economics and psychology (e.g., Frey and Oberholzer-Gee 1997). Thus, rewards can be counterproductive if they conflict with individuals' motivations or goals (Ariely et al. 2009; Deci et al. 1999). Prior research has not fully explored this idea relative to innovative offerings. We propose that the potential negative effects of a CRP program are contingent on three boundary conditions: reward visibility (i.e., disclosed to recipient or not), reward size, and reward scheme (e.g., rewards only to recommenders or to both parties).

We test these predictions in a field experiment and four online experiments, offering several contributions. First, by examining CRP effects on referral behavior for more innovative offerings (Peres et al. 2010), we enhance understanding as to the diffusion of these offerings. Extant research establishes positive interpersonal communications as critical success factors when launching innovative offerings (Kawakami and Parry 2013), but as Table 1 indicates, we know little about how firms' CRPs actually affect customers and induce diffusion. By showing that public rewards can backfire and decrease referrals, disrupting successful launches, we contribute to the new product diffusion literature (Aral 2011; Kawakami and Parry 2013).

Second, we add to the CRP effectiveness literature (see Table 1 for an overview) that focuses on design elements (e.g., reward type, reward size), brand factors (e.g., brand strength), and recommender-referral recipients relations (e.g., tie strength). Jin and Huang (2014), for example, compare monetary and in-kind rewards, showing that the former increases recommenders' perceived social costs, making them less motivating than the latter. Building on prior insights, we demonstrate that CRP effectiveness also depends on offering type. For less innovative offerings, public referral rewards can be productive, while for more innovative offerings, they may undermine referral motivations. To our knowledge, this is the first study to investigate how innovativeness of the offering affects CRP effectiveness.

Third, we also add to research on CRPs' potential negative effects. While Wirtz et al. (2013) show that CRPs can decrease positive metaperceptions, diminishing referral behavior relative to natural (unrewarded) behavior, further research is needed into the unintended, potentially negative effects of firms' customer relationship efforts (Steinhoff and Palmatier 2016). We complement Wirtz et al.'s (2013) work by illustrating the detrimental effects of referral rewards on recommenders' referral behavior for more innovative offerings.

Fourth, we offer novel insights into the motivational processes that drive referrals and how customers' motivations to engage in referrals (i.e., need to self-enhance) and extrinsic rewards (i.e., referral rewards) interact to influence referral likelihood. Prior research has examined different mechanisms underlying consumers' reactions to CRPs, including reward attractiveness (Orsingher and Wirtz 2018; Stumpf and Baum 2016), perceived social costs (Jin and Huang 2014), and metaperceptions (Wirtz et al. 2013). Yet no study explores the interplay of customers' natural (unrewarded) motivations with extrinsic rewards (e.g., referral rewards) and their effects on referral behavior. Thus, previous research fails to acknowledge that the individual positive effects of referral drivers (e.g., need to self-enhance, financial rewards) may combine to produce negative effects (Ariely et al. 2009; Bénabou and Tirole 2006). While related research notes the negative effects of financial rewards on motivation and behavior in general, it offers only limited evidence of the underlying psychological mechanisms (see Table 1). Thus, our detailed analyses of the process add insights as to the potential negative effects of incentives in a broader sense.

Fifth, there is a need to examine boundary conditions to these relationships, with the present research providing evidence that the negative effects relative to more innovative offerings (1) disappear when the reward is not visible to the referral recipient, (2) is attenuated with larger rewards, or (3) can be overcome if both parties receive rewards.

\section{Background: Drivers of customer WOM and referral behavior}

Many studies address questions about what drives word-ofmouth (WOM) and referral behaviors, defined as "informal communications between private parties concerning evaluations of goods and services" (Anderson 1998, p. 6). ${ }^{1}$ Most related research focuses on one of three motives for WOM and referrals: (1) brand- and product-related drivers, (2) psychological drivers, or (3) financial drivers (see Web Appendix A for an overview). The brand- and product-related drivers refer to consumer knowledge of and experiences with a product, service, or firm. In a comprehensive meta-analysis, de Matos and Rossi (2008) identify six common antecedents of customers' WOM and referral activities: satisfaction, loyalty, quality, commitment, trust, and perceived value, while Sundaram et al. (1998) add product involvement.

In terms of psychological factors, Dichter (1966) notes that people recommend products and services to fulfill selforiented needs or for altruistic purposes. Subsequent studies confirm and expand this reasoning, indicating that customer communication can be driven by, for example, self-oriented motives (e.g., self-enhancement), social bonding (e.g.,

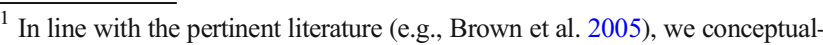
ize WOM to include recommendations and referral behaviors.
} 


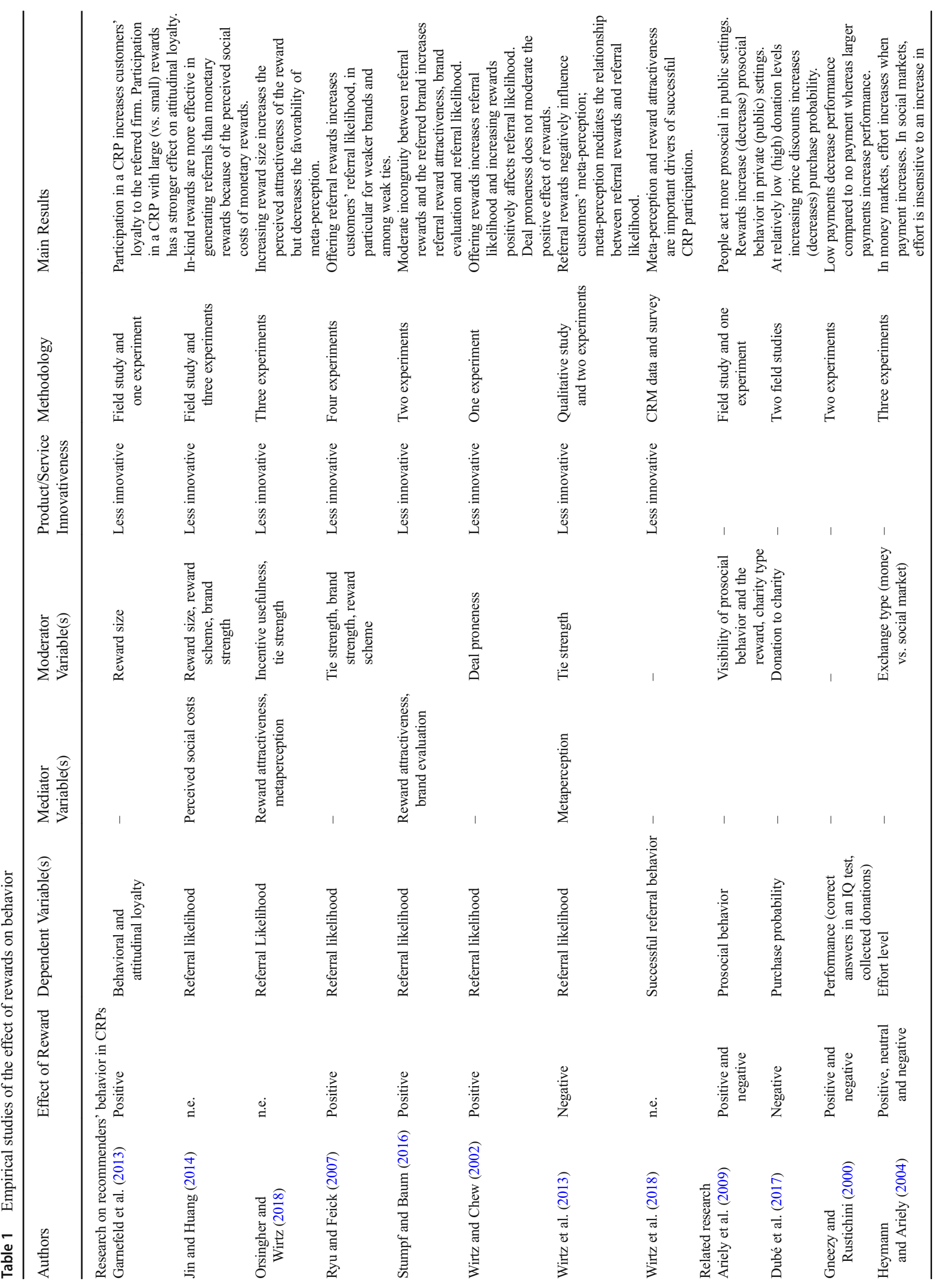




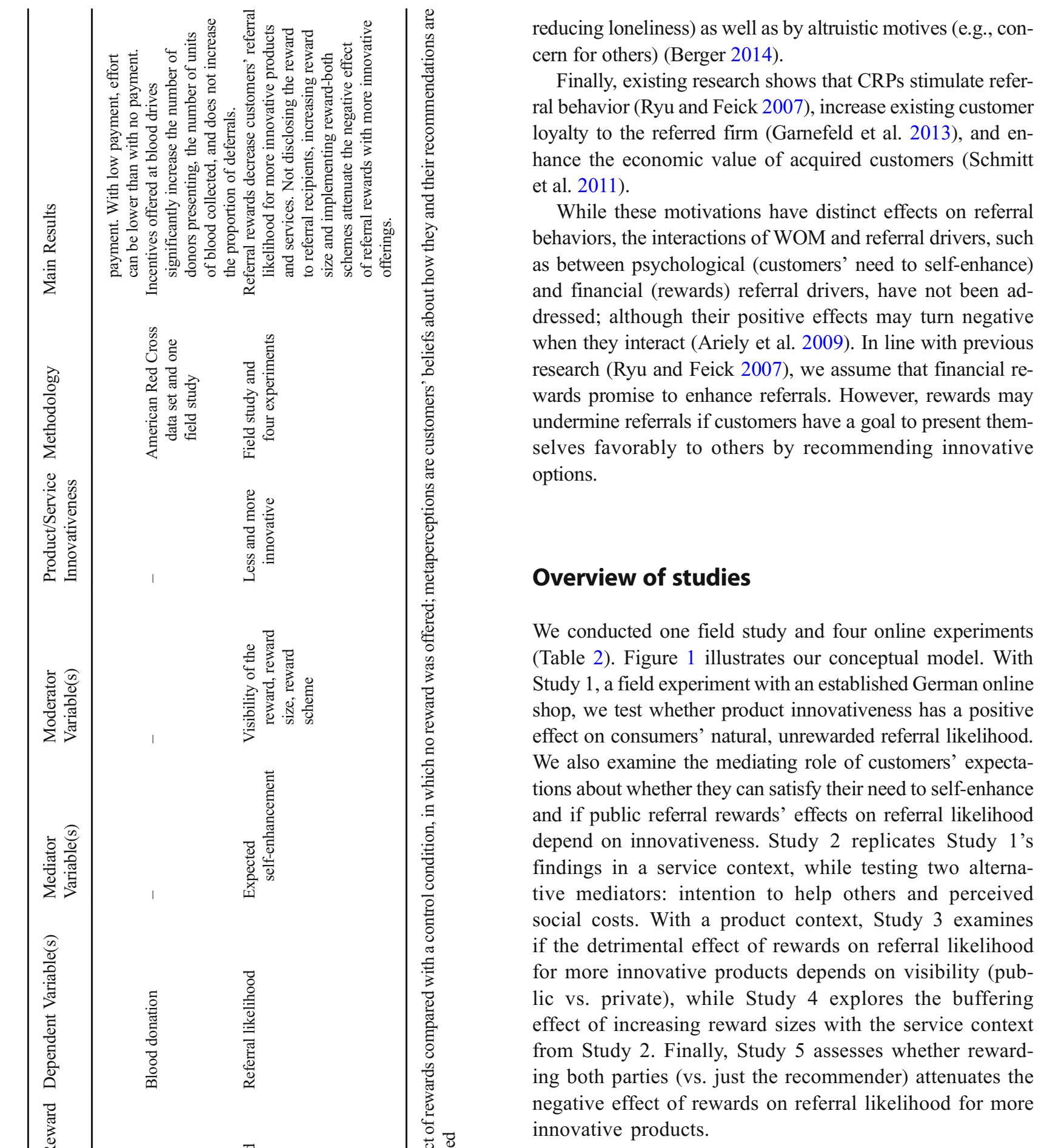

\section{Study 1: Field experiment}

In Study 1, we test our basic hypothesis that, due to customers' expectations of satisfying their self-enhancement needs, innovativeness has a positive effect on referral likelihood. We also test whether public referral rewards undermine the positive effect of innovativeness on referral likelihood. 


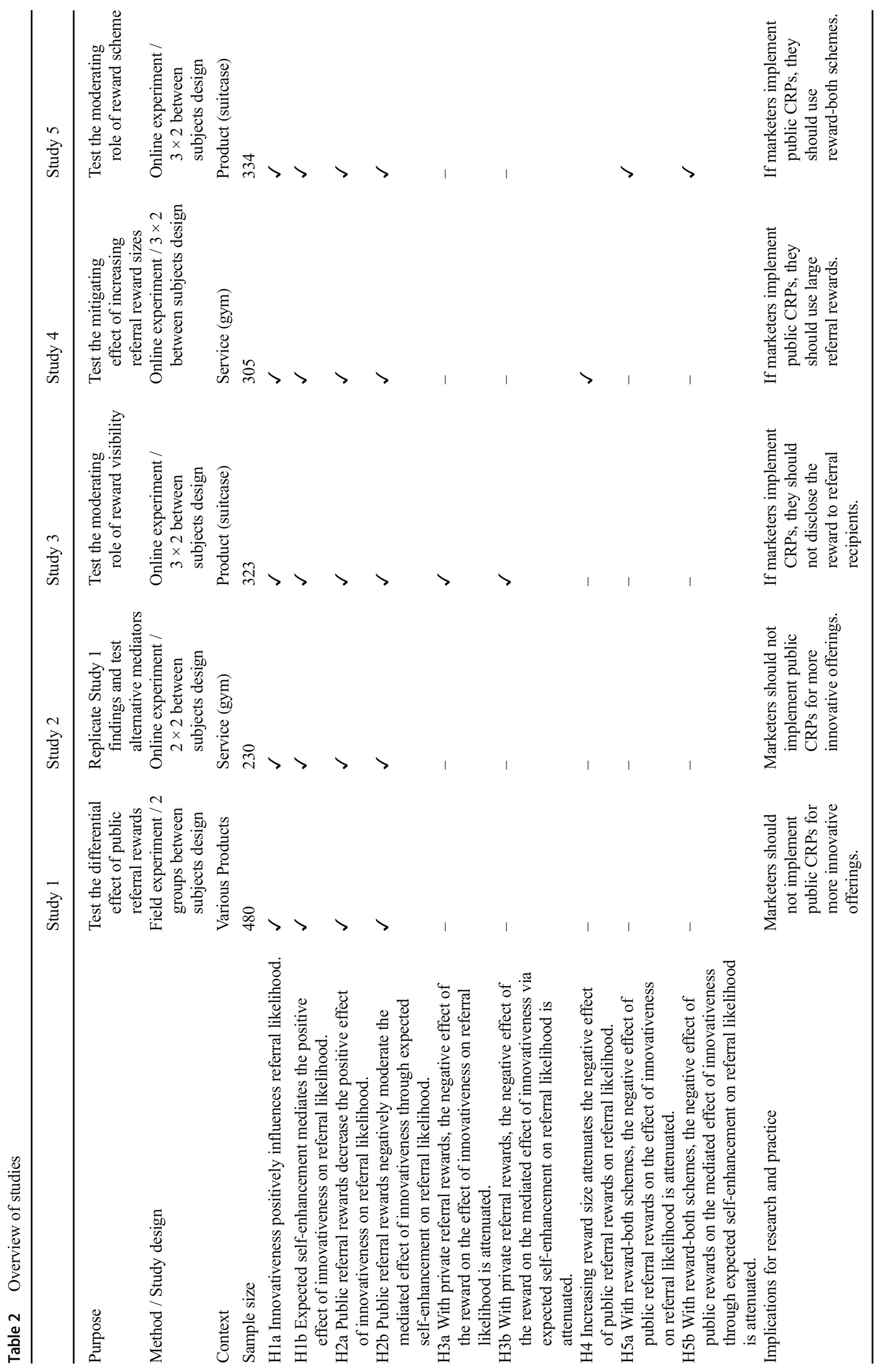


Fig. 1 Conceptual model

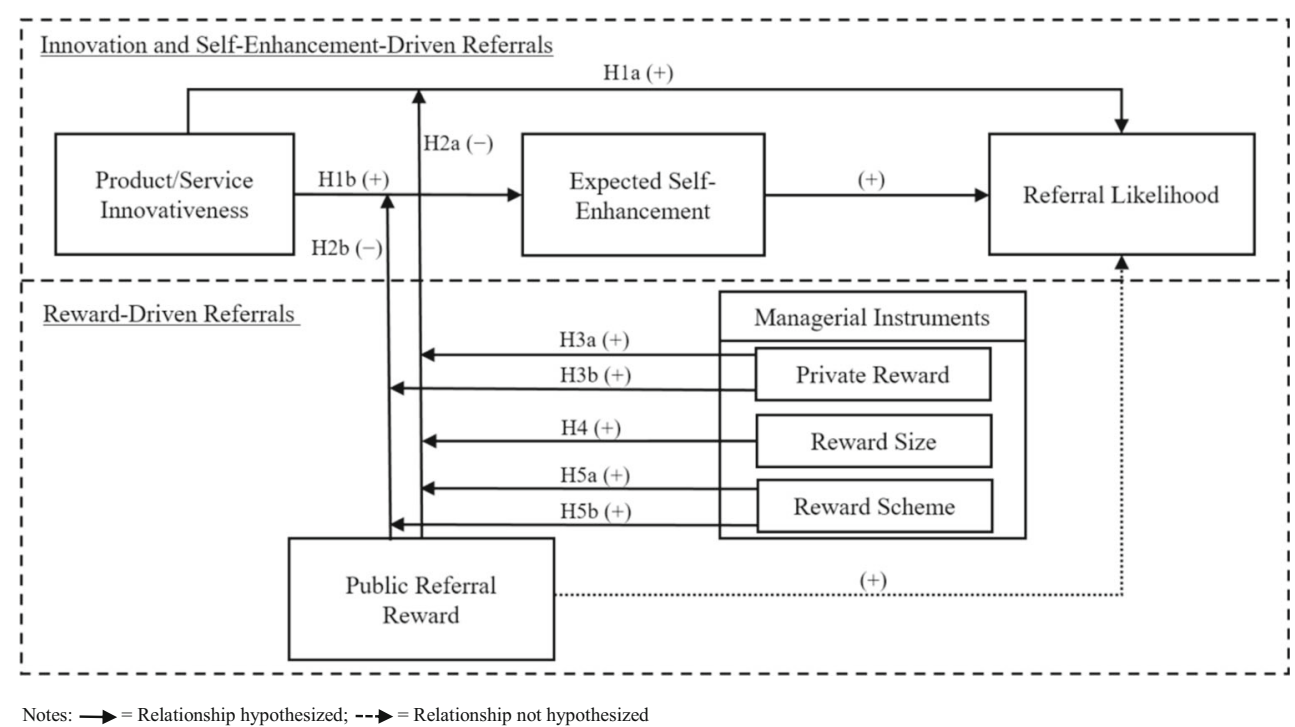

\section{Self-enhancement drives referrals of innovative products and services}

Self-enhancement theory states that humans desire to view themselves positively (Swann et al. 1989), with selfenhancement attempts occurring either privately or publicly (Sedikides and Gregg 2008). We focus on the public form, in which people use strategies to self-enhance, such as displaying abilities or sharing insights about interesting offerings (Berger 2014). In these situations, the overarching goal is to signal positive traits (Bénabou and Tirole 2006). As viable tools for public self-enhancement (Alexandrov et al. 2013; Wojnicki and Godes 2008), referral behavior of innovative offerings helps consumers present themselves favorably, fulfilling their self-enhancement needs.

Innovative offerings are novel, unique, and different from previous offers (Katila and Ahuja 2002). Providing referrals for novel offerings allows consumers to associate themselves with these positive attributes, express their uniqueness, gain social approval and appear helpful (Brown et al. 1988), thus, satisfying self-enhancement needs by referring innovative offerings.

H1a: Innovativeness positively influences referral likelihood.

H1b: Customers' expectations that they can satisfy their need for self-enhancement mediates the positive effect of innovativeness on referral likelihood, such that innovativeness increases their expectations in relation to their need to self-enhance, which in turn increases their referral likelihood.

\section{Detrimental effects of public referral rewards}

According to principal-agent theory, financial rewards increase motivation by increasing the monetary benefits of the activity (e.g., Alchian and Demsetz 1972). For example, Ryu and Feick (2007) find that offering referral rewards increases referral likelihood. However, referral rewards can hinder recommenders' perceptions relative to their beliefs about how recommendations are viewed by others (Wirtz et al. 2013).

In line with this notion, behavioral economics and psychology research provides compelling evidence that financial rewards can decrease motivation to perform behaviors in some cases (Frey and Oberholzer-Gee 1997). Financial rewards can weaken or even reverse the behaviors' social signals, because rewards may create doubt about why the person engaged in the action and decrease both motivation and actual behavior (Gneezy and Rustichini 2000).

For more innovative offerings, referral rewards may conflict with motivation to self-enhance through referrals. Thus, with a public reward, individuals may feel that the reward drove their behavior rather than their motivation to self-enhance. This perception likely is inconsistent with their attempts to feel good about themselves or to make positive impressions on others. Thus, public referral rewards may undermine recommenders' self-enhancement efforts and decrease their referral likelihood for more innovative offerings. In contrast, less innovative offerings do not invoke the same self-enhancement motivations, since these referrals are based on their instrumental value.

H2a: Public referral rewards decrease the positive effect of innovativeness on referral likelihood.

$\mathrm{H} 2 \mathrm{~b}$ : Public referral rewards negatively moderate the mediated effect of innovativeness through customers' expectations to satisfy their need to selfenhance on referral likelihood by suppressing the positive effect of innovativeness on customers' expected self-enhancement. 


\section{Participants, design, and procedure}

We conducted a field experiment in collaboration with an established German online shop that offers a wide range of products, such as books, watches, clothing, and electronic devices. It provided email addresses for 33,630 customers who had made purchases in the four weeks before our study. We randomly selected $10 \%(n=3363)$ and invited them to participate in a short survey about their last purchase in an email, issued by the online shop. The email explained that the online shop was interested in customer feedback and contained a link to the survey. Of those invited, 607 responded (18.05\%). We dropped 127 customers (20.9\%) who had incomplete responses (i.e., more than $25 \%$ of questions unanswered), resulting in a sample of $480\left(27.5 \%\right.$ women, $\left.M_{\text {age }}=48.89\right)$.

Participants first indicated the product they had last purchased from the online shop and then answered all questions with respect to that product. We measured their perceptions of the innovativeness of the purchased product, their expectations of satisfying their need to self-enhance, and their product involvement and product satisfaction. Then, we randomly assigned participants to the public referral reward or natural referral (no-reward) condition. In the former, participants read that the online shop recently launched a CRP and they would receive a $€ 5(\sim \$ 6)$ referral reward if they recommended the product to someone who then purchased it. We informed the participants that referral recipients need to indicate the recommenders' name and e-mail address when purchasing at the online shop so that recommenders could receive the reward. We did not include this information in the no-reward condition.

\section{Measures}

Participants indicated their referral likelihood on a scale anchored by $0 \%$ ("certain not to recommend the product") and $100 \%$ ("certain to recommend the product"). ${ }^{2}$ The other measures relied on multi-item, 7-point, Likert-type scales ranging from 1 ("strongly disagree") to 7 ("strongly agree"). We measured perceived innovativeness with a three-item scale from Stock (2011). Participants' expectations of satisfying their self-enhancement needs when recommending the product was measured with three items from Alexandrov et al. (2013, p. 533), who define this construct as "the degree to which a person expects that projecting a good image to others can be accomplished by sharing information about brands." Product involvement (four items, Beatty and Talpade 1994) and satisfaction with the purchased product (three items, De Wulf et al. 2001) served as covariates in our analyses. Product

\footnotetext{
${ }^{2}$ In this research domain, the term "recommend" typically applies consumers who refer a product to someone else, whether for a reward or not (see Jin and Huang 2014; Ryu and Feick 2007).
}

involvement reflects consumers' enduring perceptions of the importance of a product category, according to their inherent needs and interests (Mittal 1995); we used it to assess the personal relevance of the purchased product. The confirmatory factor analysis revealed acceptable fit with the data: $\chi^{2} / d f=$ 2.32 , confirmatory fit index $=.98$, goodness-of-fit index $=.96$, and root mean error of approximation $=.05$. The composite reliability values ranged from .83 to .96 , above the recommended threshold of 7 (Bagozzi and Yi 2012). Items for all five studies and their reliabilities appear in the Appendix. We adopted procedural remedies to minimize common method variance (Hulland et al. 2018; see Web Appendix B for detailed descriptions of the procedural remedies). A native English speaker, raised bilingually in Germany, translated the measures (for all studies) to German. A bilingual native speaker of German then translated the measures back into English (Douglas and Craig 2007). To check the referral reward manipulation, we asked participants to indicate whether the online shop offered a referral reward (no or yes). All participants answered correctly.

\section{Results}

Table 3 provides an overview of the descriptive statistics for the independent variable, the mediator variable, the outcome variable, and the covariates. We conducted a moderated mediation analysis (Hayes 2013; Model 8, with the moderator located between the independent variable and the mediator, as well as between the independent variable and the dependent variable; bootstrapped with 5000 draws), with innovativeness as the independent variable, referral reward $(0=$ no reward; $1=$ public referral reward) as moderator, expected selfenhancement as mediator, and referral likelihood as the dependent variable (Fig. 1). Product involvement and product satisfaction served as covariates. The regression models predicting customers' expectations of satisfying self-enhancement needs $\left(R^{2}=.30\right)$ and referral likelihood $\left(R^{2}=.33\right)$ both explain significant variance in the outcome variable (see Table 4).

For the direct effect of innovativeness on referral likelihood, contingent on the public referral reward, results are consistent with predictions that innovativeness positively affects referral likelihood in the absence of a referral reward

Table 3 Means, standard deviations, and correlations, Study 1

\begin{tabular}{lllllll}
\hline Variable & Mean & SD & 1 & 2 & 3 & 4 \\
\hline 1. Product innovativeness & 4.22 & 1.58 & & & & \\
2. Expected self-enhancement & 4.12 & 1.53 & $.41^{* *}$ & & & \\
3. Referral likelihood & 63.14 & 26.02 & $.27^{* *}$ & $.50^{* *}$ & & \\
4. Product involvement & 4.97 & 1.27 & $.47^{* *}$ & $.45^{* *}$ & $.33^{* *}$ & \\
5. Satisfaction & 5.83 & 1.42 & $.38^{* *}$ & $.34^{* *}$ & $.24^{* *}$ & $.65^{* *}$ \\
\hline${ }^{* *} p<.01$ & & & & & &
\end{tabular}


Table 4 Moderated mediation results, Study 1

Consequences

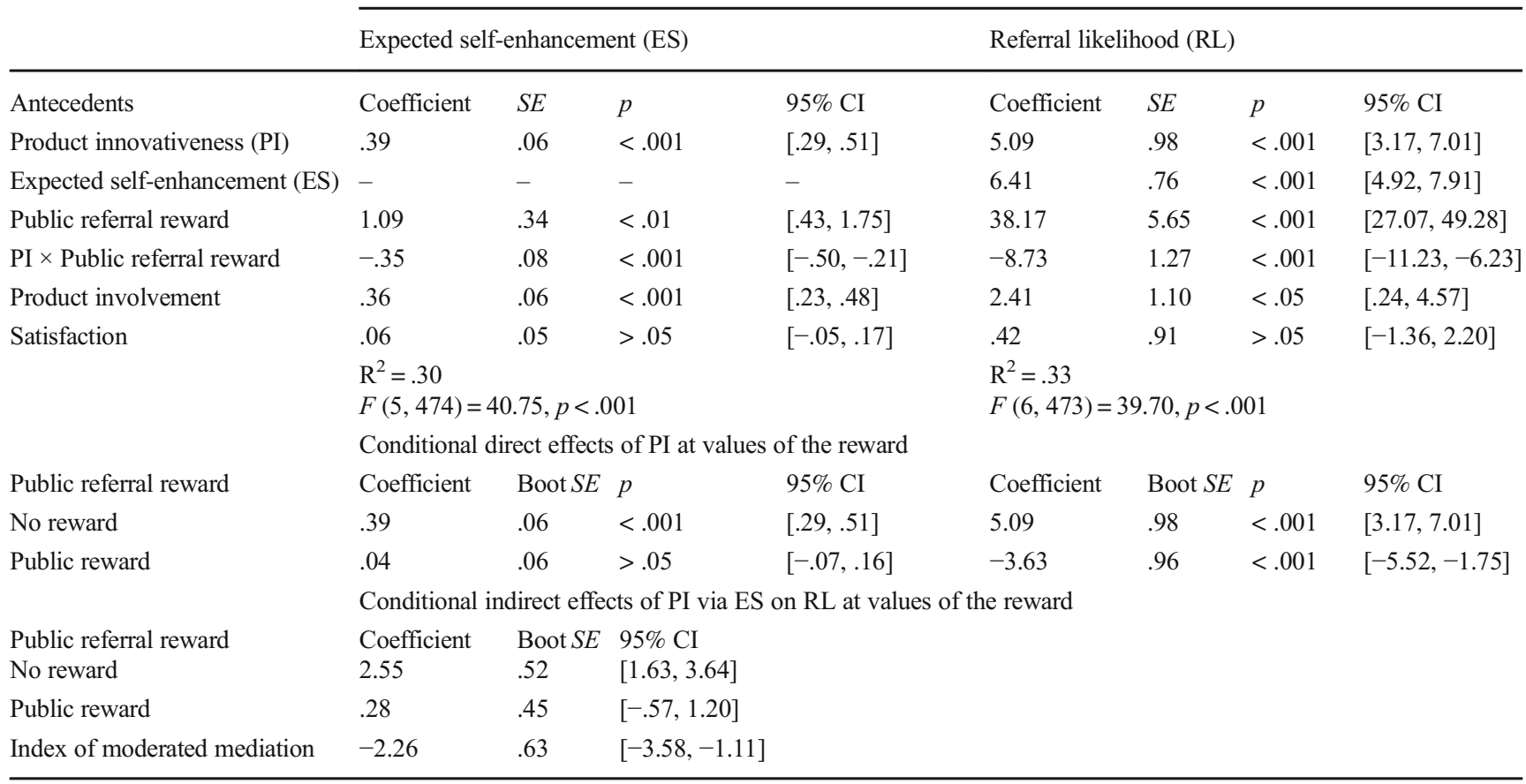

Coefficient $=$ unstandardized regression coefficients

(H1a), while a public reward decreases the effect of innovativeness on referral likelihood (H2a), noting the interaction of innovativeness and referral reward on referral likelihood $(b=$ $-8.73, S E=1.27, p<.001,95 \%$ confidence interval $[C I]=[-11.23,-6.23])$. In support of H1a, the conditional direct effects show that innovativeness positively influences referral likelihood when there is no reward $(b=$ 5.09, $S E=.98, p<.001,95 \% \mathrm{CI}=[3.17,7.01]$; Table 4), while consistent with $\mathrm{H} 2 \mathrm{a}$, the effect of innovativeness on referral likelihood is negative with a public reward (vs. no-reward $)(b=-3.63, S E=.96, p<.001,95 \%$ $\mathrm{CI}=[-5.52,-1.75]$; see Figure W1 in Web Appendix C for a simple slope analysis of innovativeness at one standard deviation below and above the mean score in the no reward and the public reward conditions).

Next, we examine the indirect effects of innovativeness through expected self-enhancement on referral likelihood, contingent on a public referral reward ( $\mathrm{H} 1 \mathrm{~b}$ and $\mathrm{H} 2 \mathrm{~b})$. The significant index of moderated mediation $(b=-2.26$, $S E=.63,95 \% \mathrm{CI}=[-3.58,-1.11])$ indicates that the reward moderates the indirect effect. Supporting H1b, expectations of satisfying self-enhancement mediate the effect of innovativeness on referral likelihood in the no-reward condition $(b=$ $2.55, S E=.52,95 \% \mathrm{CI}=[1.63,3.64])$. In the no-reward condition, innovativeness positively influences customer expectations $(b=.39, S E=.06, p<.001,95 \% \mathrm{CI}=[.29, .51])$ and self-enhancement positively affects referral likelihood $(b=$
6.41, $S E=.76, p<.001,95 \% \mathrm{CI}=[4.92,7.91]$; Table 4). Taken with the positive direct effect of innovativeness on referral likelihood in the no-reward condition, partial mediation is indicated, supporting H1b. However, self-enhancement does not mediate the effect of innovativeness on referral likelihood with a public reward $(b=.28, \mathrm{SE}=.45,95 \%$ $\mathrm{CI}=[-.57,1.20])$. Consistent with $\mathrm{H} 2 \mathrm{~b}$, public referral rewards suppress the positive effect of innovativeness on expected self-enhancement $(b=.04, S E=.06, p>.05,95 \%$ $\mathrm{CI}=[-.07, .16])$

\section{Discussion}

The results from this field study elucidate the differential effects of public referral rewards on referral likelihood and reveal important insights about their effectiveness. Thus, Study 1 provides initial evidence for the counterintuitive, surprising effect of public referral rewards on referral likelihood for more innovative offerings. As expected, the results also reveal that customers' expectations of satisfying their need for selfenhancement underlie the positive effect of innovativeness on referral behavior. However, a public referral reward undermines self-enhancement and decreases referral likelihood. To explore these detrimental effects and replicate findings in a service context, we examine the underlying mechanisms in more detail in the next experiment. 


\section{Study 2: Testing alternative mediators}

With Study 2, we pursue three objectives. First, we attempt to replicate the field study in a more controlled setting to increase confidence in our findings. Second, Study 2 can increase the generalizability of our Study 1 findings, because we use a service context instead of a product context. The intangible, experiential nature of services makes referral behavior even more important for customer acquisition, especially of a new innovative service (Bansal and Voyer 2000). Customer referrals reduce the perceived risk associated with service consumption for new customers (Murray and Schlacter 1990) and may facilitate recommenders' self-enhancement needs. Third, Study 2 incorporates customers' intention to help others by making a recommendation and the social costs' perceptions of rewarded recommendations as intervening variables, so as to consider alternative mechanisms that might explain the negative effect of rewards with more innovative offerings.

\section{Intentions to help and perceived social costs as alternative mediators}

Many consumers engage in referral behavior for altruistic reasons, that is, to help others make good purchase decisions (Dichter 1966). Through interviews, Sundaram et al. (1998) find that more than $20 \%$ of WOM and referral conversations are motivated by a desire to help others avoid problems or make better purchases, while Teichmann et al. (2015) showed that altruism drives consumers' contributions to online communities. Similarly, customers may offer recommendations for more innovative offerings to help others make better purchase decisions.

Additionally, rewarding referral behavior increases the perceived social costs of making referrals, due to doubt about the recommender's motives (Ryu and Feick 2007). As Jin and Huang (2014) show, increased social costs can explain why monetary rewards are less effective for stimulating customers' referral behavior than in-kind rewards. Accordingly, the detrimental effect of referral rewards with more innovative offerings may be due to increased social costs.

\section{Participants, design, and procedure}

Study 2 uses a 2 (service innovativeness: less innovative vs. more innovative) $\times 2$ (public referral reward: no reward vs. public reward) between-subjects design. A total of 230 participants $\left(58.3 \%\right.$ women, $M_{\text {age }}=30.7$ years) were recruited from a German market research firm's professionally hosted national online panel. Participants, who received monetary incentives from the panel provider, were randomly assigned to conditions. The invitation to participate in the study directed them to a website containing the online experiment. For the service setting, participants responded to a recommendation for a gym. The offerings in our studies are incremental innovations, such that they provide new features, benefits or improvements in an existing market (Garcia and Calantone 2002). We used a fictitious brand (Active Gym), which does not resemble any existing brand. Participants were asked to imagine they had joined a new gym a few weeks ago, with a monthly membership fee of $€ 50(\sim \$ 60)$.

Next, we manipulated innovativeness, such that we described the more innovative gym as sustainable (Nidumolu et al. 2009), offering a high level of sustainable fitness to save the environment and burn calories at the same time by using energy-producing equipment that generates renewable energy. In contrast, in the less innovative service condition, the description noted a more conventional gym (e.g., with top-ofthe-line equipment including weight machines; see Web Appendix D for more detailed descriptions of the experimental manipulations).

A pretest $\left(N=51 ; 54.9 \%\right.$ women; $M_{\text {age }}=25.6$ years $)$ indicated that participants in the more innovative condition perceived the gym as more innovative $\left(M_{\text {moreinnovative }}=5.78\right.$; $\left.M_{\text {lessinnovative }}=4.04 ; t(49)=-5.69, p<.001\right)$ according to a three-item scale from Stock (2011) and expected greater satisfaction of self-enhancement needs $\left(M_{\text {moreinnovative }}=5.53\right.$; $\left.M_{\text {lessinnovative }}=4.43 ; t(49)=-5.74, p<.001\right)$ on a three-item scale from Alexandrov et al. (2013) than participants in the less innovative condition. Participants read that they had visited the gym several times and were very satisfied with the service and equipment. In the reward condition, they read that on a recent visit to the gym an employee explained that the gym had developed a CRP and members would receive a $€ 5$ ( \$6) referral reward for each member they helped acquire; the referral recipient would need to provide the recommender's name and email address upon joining the gym. This information was not included in the no-reward condition. The referral reward size was relative to the monthly membership fee, equivalent to $10 \%$ of the monthly fee (Ryu and Feick 2007).

\section{Measures}

Participants indicated their referral likelihood on a 100-point scale $(0 \%=$ "certain not to recommend the gym"; $100 \%=$ "certain to recommend the gym"). As in Study 1, we measured participants' expectations of satisfying selfenhancement needs and product involvement. With the three-item scale from Stock (2011), we checked the innovativeness manipulation. We measured customers' intention to help others with three items from Alexandrov et al. (2013) and their perceived social costs with five items from Jin and Huang (2014). In addition, we included a three-item CRP proneness scale from Lichtenstein et al. (1990), which served as a covariate. The CRP proneness measure describes a 
general tendency to participate in CRPs. We also asked participants whether the firm offered a referral reward. Two realism checks (Darley and Lim 1993) affirmed the realism of our setting $(M=5.20, S D=1.35)$.

\section{Results}

Manipulation checks The manipulations of innovativeness and the referral reward were successful (see Web Appendix E for detailed manipulation checks).

Hypotheses tests We conducted a moderated mediation analysis (Hayes 2013; Model 8; bootstrapped with 5000 draws), with innovativeness ( $0=$ less innovative; $1=$ more innovative) as the independent variable; referral reward $(0=$ no reward; $1=$ public reward $)$ as a moderator, expected self-enhancement, customers' intention to help others, and perceived social costs as mediator variables, and referral likelihood as the dependent variable. Product involvement and CRP proneness served as covariates. Table 5 shows the results of the moderated mediation model and the effects of innovativeness on referral likelihood through the three mediator variables. The regression models predicting expectations of satisfying selfenhancement needs $\left(R^{2}=.35\right)$, intention to help others $\left(R^{2}=.27\right)$, perceived social costs $\left(R^{2}=.12\right)$, and referral likelihood $\left(R^{2}=.32\right)$ explain significant variance in the outcome variable.

As in Study 1, we first examine the direct effect of innovativeness on referral likelihood, contingent on the public referral reward (H1a and H2a). Consistent with our predictions, we find a two-way interaction effect of innovativeness and the reward on referral likelihood $(b=-27.06, S E=6.11$, $p<.001,95 \% \mathrm{CI}=[-39.09,-15.02]$; Table 5$)$. The conditional direct effects reveal that innovativeness positively affects referral likelihood in the absence of a reward $(b=$ $17.46, S E=4.48, p<.001,95 \% \mathrm{CI}=[8.63,26.28])$, in support of H1a. Participants' natural, unrewarded referral likelihood is higher in the more versus less innovative service condition $\left(M_{\text {moreinnovative }}=80.04 ; M_{\text {lessinnovative }}=58.86\right.$; $t(105)=-5.03, p<.001$; see Figure W2 in Web Appendix C). In support of H2a, there is a negative direct effect of innovativeness on referral likelihood in the public reward condition $(b=-9.59, S E=4.10, p<.05,95 \% \mathrm{CI}=[-17.68$, $-1.52])$. The cell means reveal that introducing a public referral reward for a more innovative service decreases referral likelihood (vs. no reward) $\left(M_{\text {noreward }}=80.04\right.$; $\left.M_{\text {publicreward }}=62.20 ; t(105.54)=3.68, p<.001\right)$, while doing so for a less innovative service increases referral likelihood (vs. no reward) $\left(M_{\text {noreward }}=58.86 ; M_{\text {publicreward }}=74.37\right.$; $t(112)=-3.38, p<.001)$.

Next, we examined the indirect effects of innovativeness through expected self-enhancement on referral likelihood, contingent on the public referral reward ( $\mathrm{H} 1 \mathrm{~b}$ and $\mathrm{H} 2 \mathrm{~b}$ ). The significant index of moderated mediation $(b=-5.67, S E=2.97,95 \% \mathrm{CI}=[-12.54,-1.12])$ indicates that the indirect effect of innovativeness through expected self-enhancement on referral likelihood is moderated by the reward. Supporting H1b, expectations of satisfying self-enhancement mediate the effect of innovativeness on referral likelihood in a no-reward case $(b=4.75, S E=$ $1.98,95 \% \mathrm{CI}=[1.53,9.18])$. With no reward, innovativeness positively influences expected satisfaction of selfenhancement $(b=.72, S E=.23, p<.01,95 \% \mathrm{CI}=[.27$, $1.17])$, which then positively influences referral likelihood $(b=6.59, S E=1.36, p<.001,95 \% \mathrm{CI}=[3.91,9.26]$, indicating partial mediation. As predicted in $\mathrm{H} 2 \mathrm{~b}$, expected self-enhancement does not mediate the effect of innovativeness on referral likelihood in the public reward condition $(b=-.93, \mathrm{SE}=1.65,95 \% \mathrm{CI}=[-4.91,1.57]$; see Table 5); the public referral reward suppresses the positive effect of innovativeness on expected self-enhancement $(b=-.14, S E=.21, p>.05,95 \% \mathrm{CI}=[-.56, .28])$.

The tests of the two alternative mediators (intention to help others and perceived social costs) in our moderated mediation model reveal that offering a reward decreases customers' intention to help others $(b=-.40, S E=.20, p<.05,95 \%$ $\mathrm{CI}=[-.80,-.01])$ and increases perceived social costs $(b=.94, S E=.25, p<.001,95 \% \mathrm{CI}=[.45,1.43]$; see Table 5). In line with previous research (Jin and Huang 2014), perceived social costs also negatively affect referral likelihood $(b=-2.86, S E=1.19, p<.05,95 \% \mathrm{CI}=[-5.21$, $-.52])$. However, the conditional indirect effects indicate that neither intentions to help $(b=.06, S E=.59,95 \% \mathrm{CI}=[-1.41$, 1.18]) nor perceived social costs $(b=.09, S E=1.07,95 \%$ $\mathrm{CI}=[-2.39,2.21])$ mediate the effect of innovativeness on referral likelihood.

\section{Discussion}

Using an online experiment, Study 2 replicates Study 1 in a service context. We again identify a negative effect of public referral rewards on referral likelihood with more innovative offerings. For more innovative services, customers exhibit high natural, unrewarded referral likelihood, but when offered a reward, their referral likelihood decreases. For less innovative services though, public referral rewards trigger a standard economic reward effect that increases participants' referral likelihood compared with the no-reward condition. Study 2 also rules out the alternative mediators, providing additional support for self-enhancement as the underlying mechanism. Studies 1 and 2 together provide strong support for our theoretical predictions, revealing important insights about the negative effects of public rewards on referral likelihood for more innovative offerings. Further, the direct effect of 
Table 5 Moderated mediation results, Study 2

Consequences

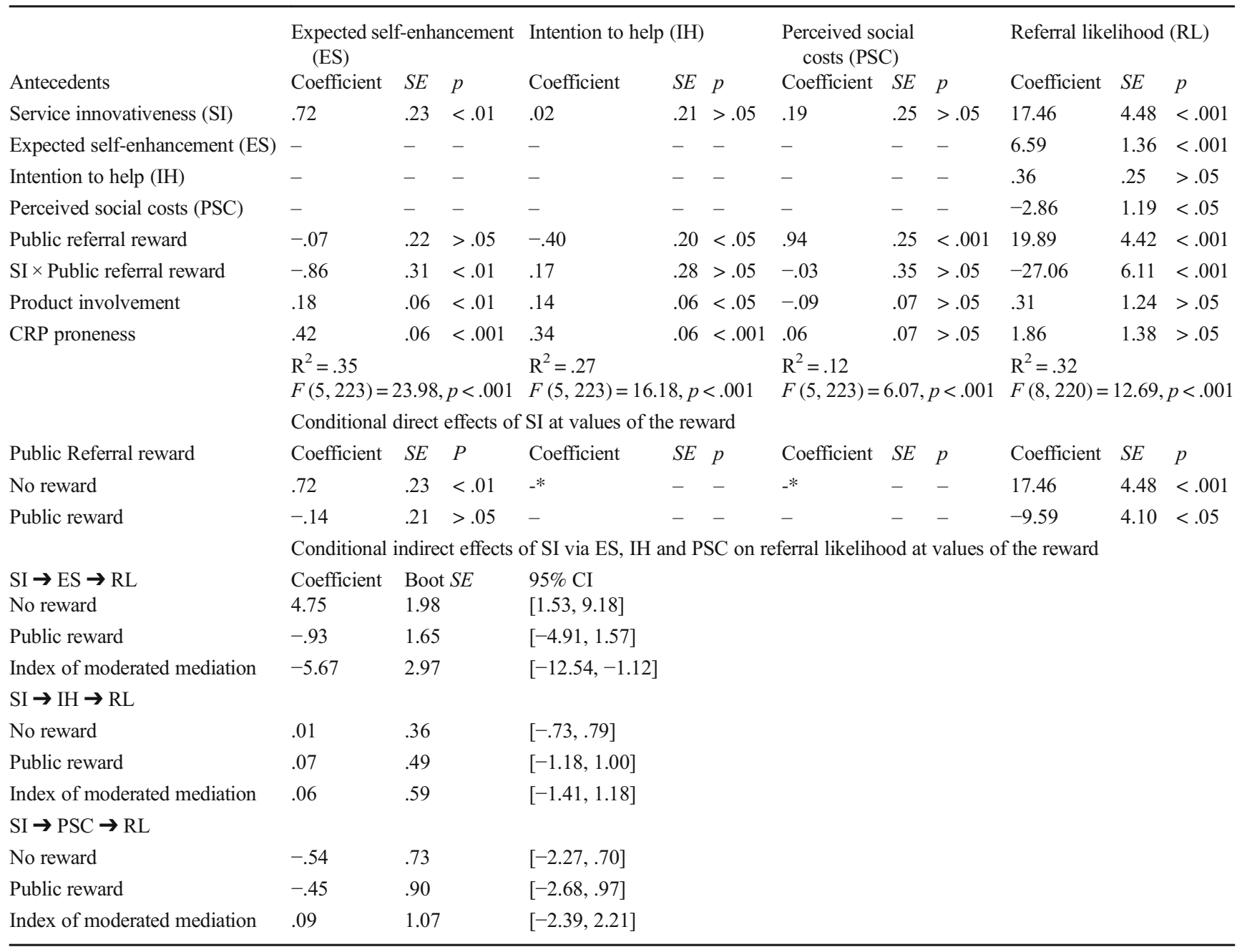

Coefficient $=$ unstandardized regression coefficients

*The conditional direct effects of service innovativeness at the values of the reward on intention to help and perceived social costs are not calculated in the Process macro, because the interaction effects of service innovativeness and the referral reward on intention to help and perceived social costs are not significant

the public referral reward on referral likelihood is stronger in Study 1, possibly due to the greater realism of the field experiment.

\section{Study 3: Moderating role of reward visibility}

In Study 3, we investigate whether reward visibility (public vs. private) affects the negative effect of rewards on referral behavior with more innovative offerings. In most CRPs, the referral reward is visible to both the recommender and the referral recipient (public condition), yet some programs hide this information (private condition). Study 3 tests whether firms can mitigate the negative effect of referral rewards by not disclosing the reward to referral recipients.

\section{Public versus private referral rewards}

The detrimental effect of referral rewards for more innovative offerings identified in Studies 1 and 2 is likely a consequence of the conflict between a public referral reward and the recommender's attempt to make positive impressions on others. In situations in which people are driven (partly) by others' perceptions, it is crucial to specify whether their motivation and actions are visible to others. In field experiments, Ariely et al. (2009) and Ashraf et al. (2014), for example, find that monetary incentives have neutral or negative effects on prosocial behavior in public settings but positive effects in private settings.

Thus, referral reward visibility is an important boundary condition of the proposed effects. That is, rewards may 
undermine recommenders' need to present themselves favorably to others only if they are visible to the recipient (public condition). If the reward is not disclosed to the recipient, it may not undermine recommenders' self-enhancement needs or referral behavior (private condition).

H3a: With a private (vs. public) referral reward, the negative effect of the reward on the effect of innovativeness on referral likelihood is attenuated.

H3b: With a private (vs. public) referral reward, the negative effect of the reward on the mediated effect of innovativeness through expected self-enhancement on referral likelihood is attenuated.

\section{Participants, design, and procedure}

Study 3 uses a 3 (referral reward: no vs. public vs. private) $\times$ 2 (product innovativeness: less vs. more) between-subjects design. As in Study 2, we recruited participants from a German market research firm's hosted national online panel. In total, 325 participants $\left(62.2 \%\right.$ women, $M_{\text {age }}=30.3$ years $)$ took part and were randomly assigned to the conditions. We used suitcases as the product category. The use of CRPs is widespread among firms selling suitcases, and most people are familiar with suitcases, so they can readily identify more innovative product characteristics. We developed a fictitious brand (Smart Trolley) to avoid any influence of prior brand beliefs, with no resemblance to any existing brand. Participants imagined that they had bought a new suitcase for $€ 200(\sim 240)$ a few weeks ago. As in prior research (Truong et al. 2017), participants read descriptions of suitcases that varied in innovativeness. In the more innovative condition, the suitcase had various innovative features (e.g., integrated GPS and $3 \mathrm{G}$ technology). In the less innovative product condition, participants read a description of a suitcase with standard equipment (see Web Appendix D for more detailed descriptions of the experimental manipulations). A pretest $\left(N=57 ; 45.60 \%\right.$ women; $M_{\mathrm{age}}=$ 25.42 years) indicated that participants in the more innovative product condition perceived the suitcase as more innovative $\left(M_{\text {moreinnovative }}=5.81 ; M_{\text {lessinnovative }}=4.08 ; t(42.41)=\right.$ $-5.38, p<.001)$ according to a three-item scale from Stock (2011). They also expressed greater expected satisfaction of self-enhancement needs than participants in the less innovative condition $\left(M_{\text {moreinnovative }}=4.02 ; M_{\text {lessinnovative }}=2.96\right.$; $t(55)=-2.59, p<.05)$ on a three-item scale from Alexandrov et al. (2013). In both the public and private reward conditions, participants read that Smart Trolley sent them an email, announcing the launch of a CRP. If they recommended the product to someone who then purchased a Smart Trolley suitcase, the firm would pay them $€ 30$ ( $\sim 36)$. In the public reward condition, participants read that the referral recipient would need to provide the recommender's name and email address when purchasing for the recommender to receive the reward. In the private reward condition, participants instead read that the recommender would need to provide the referral recipient's name and email address but Smart Trolley would not disclose the reward to the recipient. We did not include this information in the no-reward condition. The reward sizes are at a medium level, equivalent to $15 \%$ of the selling price.

\section{Measures}

Participants indicated their referral likelihood on a 100-point scale $(0 \%=$ "certain not to recommend the suitcase"; $100 \%=$ "certain to recommend the suitcase"). As in Study 2, we measured expectations of satisfying self-enhancement needs, product involvement, and CRP proneness. The same threeitem scale (Stock 2011) served to check the manipulation of innovativeness. In addition, we asked participants whether the firm offered a referral reward. To check the reward visibility manipulation, we asked participants to indicate whether the recipient knew that a referral reward was paid to the recommender. Two realism checks (Darley and Lim 1993) affirmed the realism of our experimental setting $(M=5.06$, $S D=1.50)$.

\section{Results}

Manipulation checks The manipulation of innovativeness was successful. However, two participants who answered incorrectly relative to the visibility of the reward were excluded, with a final sample of 323 (see Web Appendix E for detailed manipulation checks).

Hypotheses tests To test $\mathrm{H} 3 \mathrm{a}$ and $\mathrm{b}$, we conducted a moderated mediation analysis (Hayes 2013; Model 8; bootstrapped with 5000 draws), with innovativeness ( $0=$ less innovative; $1=$ more innovative) as the independent variable, referral reward $(0=$ no reward; $1=$ public reward; $2=$ private reward) as a moderator, expected self-enhancement as a mediator, referral likelihood as the dependent variable, and product involvement and CRP proneness as covariates. Because the moderator is a multi-categorical variable with three conditions, we created two dummy variables for the analyses. Dummy 1 reflects the difference between the public reward and no-reward conditions; Dummy 2 refers to the difference between the private reward and no-reward conditions. The no-reward condition thus serves as the reference category. Table 6 contains the results of the moderated mediation model.

Corroborating Studies 1 and 2, and in support of H1a, we find a positive direct effect of innovativeness on referral likelihood when no reward is offered $(b=11.53, S E=5.34$, 
Table 6 Moderated mediation results, Study 3

Consequences

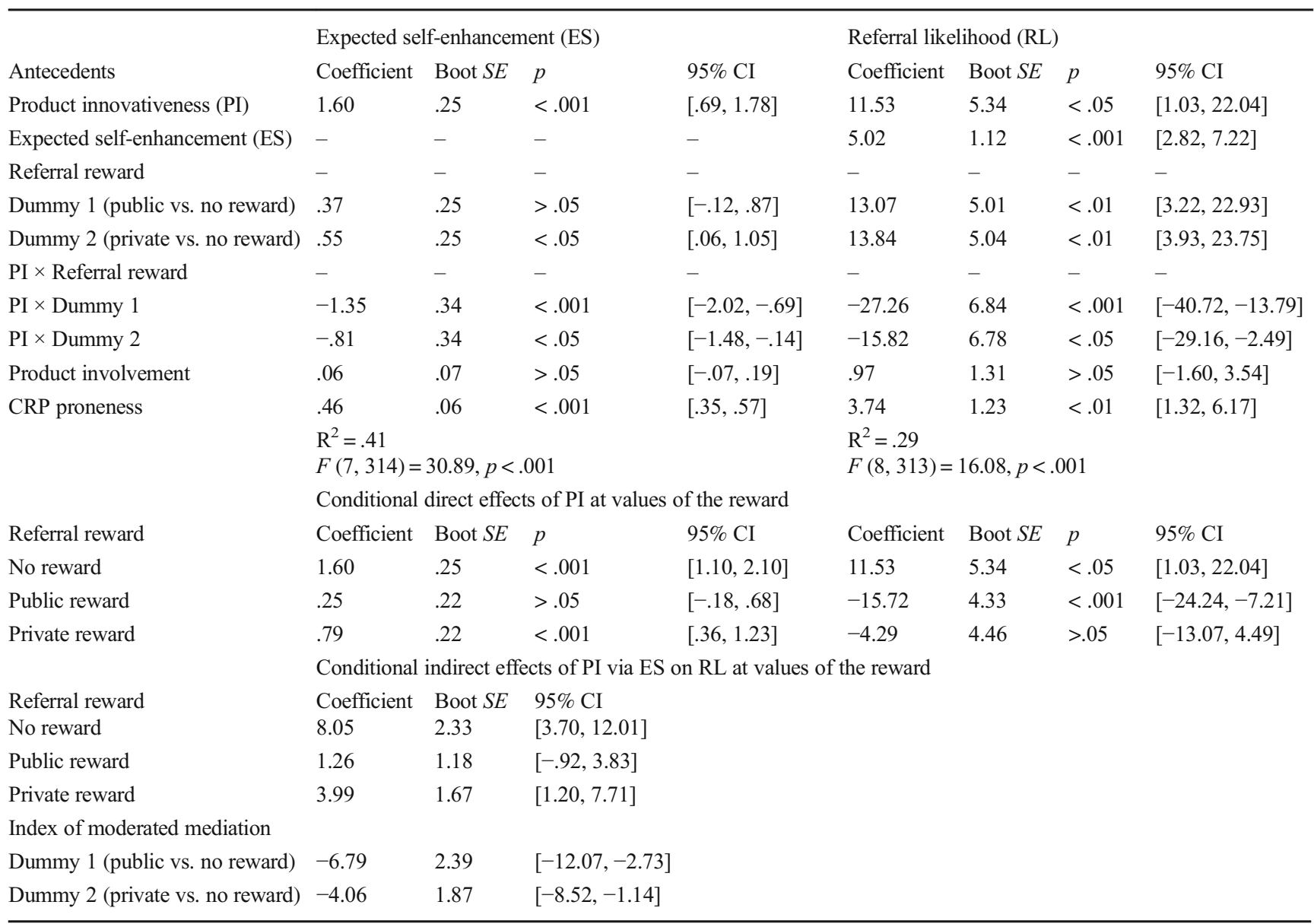

Coefficient $=$ unstandardized regression coefficients; Dummy 1 reflects the difference between the public reward and no-reward conditions; Dummy 2 reflects the difference between the private reward and no-reward conditions

$p<.05,95 \% \mathrm{CI}=[1.03,22.04])$. The results also reveal a negative direct effect of innovativeness on referral likelihood in the public reward condition, such that the effect of innovativeness on referral likelihood decreases relative to the noreward condition $(b=-15.72, S E=4.33, p<.001,95 \%$ $\mathrm{CI}=[-24.24,-7.21]$; Table 6). However, the effect of innovativeness on referral likelihood is not significant for a private referral reward; that is, the effect of innovativeness does not differ from that in the no-reward condition $(b=-4.29, S E=$ $4.46, p>.05,95 \% \mathrm{CI}=[-13.07,4.49])$. Offering a public referral reward with more innovative products decreases referral likelihood compared with the no-reward condition $\left(M_{\text {noreward }}=81.17 ; M_{\text {publicreward }}=58.70 ; t(84.61)=4.15\right.$, $p<.001$ ), but with a private referral reward, participants' referral likelihood is higher than in the public reward condition $\left(M_{\text {publicreward }}=58.70 ; M_{\text {privatereward }}=73.41 ; t(98.80)=-2.53\right.$, $p<.05)$ and not lower than in the no-reward condition $\left(M_{\text {noreward }}=81.17 ; M_{\text {privatereward }}=73.41 ; t(112)=1.89\right.$, $p>.05$; see Figure W3 in Web Appendix C). Thus, the negative effect of referral rewards is attenuated by private referral rewards, in support of H3a. However, we find no difference between public and private rewards for less innovative products $\left(M_{\text {publicreward }}=74.41 ; M_{\text {privatereward }}=\right.$ $75.68 ; t(114)=-.29, p>.05)$.

Regarding the indirect effect of innovativeness through expected self-enhancement on referral likelihood, contingent on the three reward conditions, Table 6 indicates the indices of the moderated mediation, reflecting the differences across the conditional indirect effects. Dummy 1 contrasts the indirect effect in the public reward condition to the indirect effect in the no-reward condition, and Dummy 2 compares the indirect effect in the private reward condition to the indirect effect in the no-reward condition. The moderated mediation indices reveal that the indirect effects in the public reward condition $(b=-6.79$, $S E=2.39,95 \% \mathrm{CI}=[-12.07,-2.73])$ and private reward 
condition $(b=-4.06, S E=1.87,95 \% \mathrm{CI}=[-8.52,-1.14])$ decrease relative to those in the no-reward condition.

As in Studies 1 and 2, expectations of satisfying selfenhancement needs mediates the effect of innovativeness on referral likelihood when no reward is offered $(b=8.05$, $S E=2.33,95 \% \mathrm{CI}=[3.70,12.01])$, in support of H1b. In the absence of a reward, innovativeness positively affects expectations of satisfying this need $(b=1.60, S E=.25, p<.001$, $95 \% \mathrm{CI}=[.69,1.78])$, which then positively affects referral likelihood $(b=11.53, S E=5.34, p<.05,95 \% \mathrm{CI}=[1.03$, 22.04]), indicating partial mediation. Expected selfenhancement does not mediate the effect of innovativeness on referral likelihood in the public referral reward condition $(b=1.26, \mathrm{SE}=1.18,95 \% \mathrm{CI}=[-.92,3.83])$; the public referral reward suppresses the positive effect of innovativeness on expected self-enhancement $(b=.25, S E=.22$, $p>.05,95 \% \mathrm{CI}=[-.18, .68])$. However, in support of $\mathrm{H} 3 \mathrm{~b}$ and consistent with our reasoning that not disclosing the reward to the referral recipient allows recommenders to satisfy self-enhancement needs, innovativeness positively affects expected self-enhancement $(b=.79, S E=.22, p<.05,95 \% \mathrm{CI}=[.36,1.23])$ and expected self-enhancement mediates the effect of innovativeness on referral likelihood in the private reward condition $(b=3.99, S E=1.67,95 \%$ CI $=[1.20,7.71]$; Table 6).

\section{Discussion}

These results provide further support for the proposed effect of innovativeness on referral likelihood via expected self-enhancement, as well as for the detrimental effect of public referral rewards with more innovative offerings. Moreover, Study 3 examines an important boundary condition of the proposed negative effect of referral rewards: Private referral rewards, which are not disclosed to the referral recipient, enable recommenders to achieve selfenhancement while attenuating the negative effect of the reward on referral likelihood. Thus, Study 3 findings provide additional support that customers' expectations of satisfying the need to self-enhance explains the detrimental effect of referral rewards for more innovative offerings.

\section{Study 4: Mitigating role of referral reward size}

Study 4 examines referral reward size as another boundary condition. When the size of the referral reward increases, its economic benefits may offset recommenders' decreasing motivation to refer more innovative offerings, and it likely reinforces the positive effects on referral likelihood for less innovative services.

\section{Increasing referral reward size}

The negative effect of financial rewards on customers' motivation and behavior may depend on the reward amount. That is, the motivating effect of large rewards tends to be greater than the loss of customers' initial motivation to self-enhance, as induced by the financial reward (Gneezy 2005), with a monotonic, increasing relationship between financial rewards for an activity and motivation expected (Prendergast 1999).

Accordingly, larger public referral rewards may mitigate the negative effects on referral likelihood for more innovative offerings, while relatively small public rewards should decrease referral likelihood compared with the no-reward condition, because small referral rewards cannot compensate for the loss of satisfying self-enhancement needs. Meanwhile, larger public referral rewards may offset this effect and increase referral likelihood, compared with smaller rewards.

H4: Increasing referral reward size attenuates the negative effect of public referral rewards on the effect of innovativeness on referral likelihood.

\section{Participants, design, and procedure}

To test H4, we use a 3 (public referral reward: no reward vs. small reward vs. large reward) $\times 2$ (service innovativeness: less vs. more) between-subjects design. A total of 305 participants (50.8\% women, $M_{\text {age }}=27.7$ years) were recruited, using the method suggested by López-López et al. (2014), and randomly assigned to the conditions. Research assistants approached people on the street and in large shopping malls in a major German city and asked them to participate in a research study, at different times and days over a ten-day period. Those who agreed to participate were given a link to the online study and asked to answer the online questionnaire in the next two days. In total, $51.8 \%$ of the people who verbally agreed to participate actually participated in the online study. As an incentive, participants could enter a raffle, in which 1 of every 25 participants could win a $€ 25(\sim 30)$ Amazon voucher.

We employed the service scenario, with the same fictitious brand (Active Gym) and service innovativeness manipulation, from Study 2, but added a reward size manipulation (no reward vs. small reward vs. large reward). For the reward size manipulation, we noted that, on a recent visit to the gym, a service employee explained that the gym had developed a CRP in which members would receive either a $€ 5$ (low) or $€ 50$ (high) referral reward for every new member they helped acquire and that the referral recipient would need to provide the recommender's name and email address when becoming a new member of the gym. We did not include this information in the no-reward condition. The determination of the reward size again was 
relative to the monthly membership fee, such that the small reward was $10 \%$ and the large reward was $100 \%$ of the monthly fee (Ryu and Feick 2007).

\section{Measures}

Participants indicated their referral likelihood on a 100-point scale $(0 \%=$ "certain not to recommend the gym"; $100 \%=$ "certain to recommend the gym"). We again measured participants' expectations of satisfying their self-enhancement needs, product involvement, and CRP proneness. The same three-item scale (Stock 2011) served to check the manipulation of innovativeness. In addition, we included a two-item scale from Ryu and Feick (2007) to check the manipulation of reward size (see Appendix). Two realism checks (Darley and Lim 1993) affirmed the realism of our experimental setting $(M=5.08, S D=1.27)$.

\section{Results}

Manipulation checks The manipulations of service innovativeness and referral reward size were successful (see Web Appendix E for detailed manipulation checks).

Hypotheses tests The moderated mediation analysis (Hayes 2013; Model 8; bootstrapped with 5000 draws) included innovativeness $(0=$ less innovative; $1=$ more innovative) as the independent variable, public referral reward $(0=$ no reward; $1=$ small reward; $2=$ large reward) as a moderator, expected self-enhancement as a mediator, referral likelihood as the dependent variable, and product involvement and CRP proneness as covariates. As in Study 3, we created two dummy variables, with Dummy 1 contrasting the small reward and no-reward conditions, and Dummy 2 comparing the large reward and no-reward conditions. The no-reward condition serves as the reference category. Table 7 contains the results of the moderated mediation model.

We find a positive direct effect of innovativeness on referral likelihood when no reward is offered $(b=11.59, S E=3.84$, $p<.01,95 \% \mathrm{CI}=[4.05,19.15])$, in support of H1a. The results also reveal negative direct effects of innovativeness on referral likelihood in the small public reward $(b=-19.82$, $S E=3.58, p<.001,95 \% \mathrm{CI}=[-26.87,-12.77])$ and in the large public reward $(b=-10.33, S E=3.28, p<.01,95 \%$ $\mathrm{CI}=[-16.79,-3.88]$; Table 7) conditions; in both these conditions, the effect of innovativeness on referral likelihood decreases relative to the no-reward condition. To analyze the innovativeness-reward size interaction in more detail, we examined the effects of public referral rewards on referral likelihood for more versus less innovative conditions separately. Introducing a small public referral reward $(€ 5)$ in the more innovative condition decreases referral likelihood
$\left(M_{\text {noreward }}=81.64 ; M_{\text {smallreward }}=51.23 ; t(111.69)=9.53\right.$, $p<.001$ ), while raising the reward size to $€ 50$ increases referral likelihood relative to the small reward condition $\left(M_{\text {largereward }}=73.20 ; M_{\text {smallreward }}=51.23 ; t(118.81)=-5.75\right.$, $p<.001$; see Figure W4 in Web Appendix C), supporting H4. ${ }^{3}$ However, referral likelihood in the large public reward condition still is lower than in the no-reward condition $\left(M_{\text {noreward }}=81.64 ; M_{\text {largereward }}=73.20 ; t(81.82)=2.76\right.$, $p<.001)$. In the less innovative condition, a small reward slightly increases referral likelihood $\left(M_{\text {noreward }}=61.18\right.$; $M_{\text {smallreward }}=69.68 ; t(63)=-1.88, p=.06 ;$ Figure W4). We also find an increase from the no-reward to the large public reward condition $\left(M_{\text {noreward }}=61.68 ; M_{\text {largereward }}=81.79\right.$; $t(43.05)=-5.41, p<.05)$, as well as from the small to large reward conditions $\left(M_{\text {smallreward }}=69.68 ; M_{\text {largereward }}=81.79\right.$; $t(46.08)=-4.01, p<.05)$.

Finally, we examined the conditional indirect effects. Dummy 1 contrasts the indirect effects in the small versus no-reward conditions, and Dummy 2 compares the indirect effects in the large versus no-reward conditions. The moderated mediation indices reveal that the indirect effects in the small public reward condition $(b=-7.16$, $S E=2.09,95 \% \mathrm{CI}=[-11.73,-3.55])$ and the large public reward condition $(b=-7.18, S E=2.06,95 \% \mathrm{CI}=[-11.63$, $-3.71]$ ) decrease relative to the no-reward condition. As expected, indirect effects indicate that expected selfenhancement mediates the effect of innovativeness on referral likelihood in the no-reward $(b=8.67, S E=1.77$, $95 \% \mathrm{CI}=[5.43,12.39])$ but not in the small reward $(b=$ $1.51, S E=1.26,95 \% \mathrm{CI}=[-.99,4.05])$ or large reward conditions $(b=1.49, S E=1.31,95 \% \mathrm{CI}=[-1.02$, 4.14]). ${ }^{4}$ These findings are consistent with our reasoning that referral rewards undermine customers' motivation to self-enhance through referrals but that large rewards can compensate for the loss of motivation and increase referral likelihood, compared with a small reward.

\section{Discussion}

Participants' referral likelihood for more innovative services decreases in the presence of small public referral rewards relative to no reward, but with Study 4, we show that this detrimental effect depends on the reward size. In line with the

\footnotetext{
${ }^{3}$ Our results reveal a U-shaped effect with regard to more innovative offerings: With no referral reward, customers' referral likelihood is high; with a small referral reward, referral likelihood decreases (vs. no-reward condition); and with a large referral reward, referral likelihood increases again (vs. noreward condition).

${ }^{4}$ A pairwise comparison of the indirect effects in the small and large reward conditions shows that the indirect effect in the small reward condition is not significantly different from the indirect effect in the large reward condition $(\mathrm{b}=-.02, \mathrm{SE}=1.80,95 \% \mathrm{CI}=[-3.66,-3.59])$.
} 
Table 7 Moderated mediation results, Study 4

Consequences

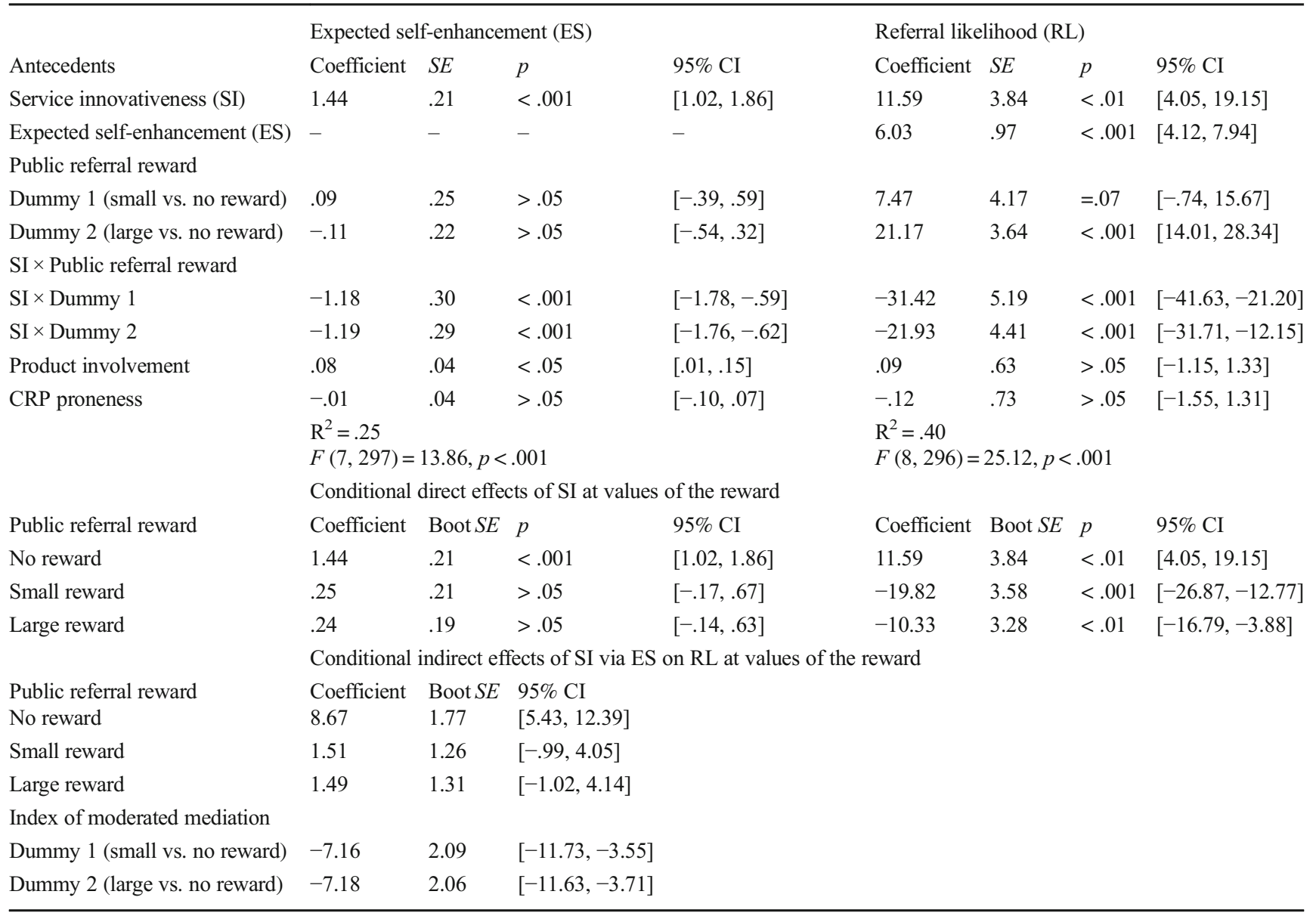

Coefficient $=$ unstandardized regression coefficients; Dummy 1 contrasts the small reward and no-reward conditions; Dummy 2 compares the large reward and no-reward conditions

rationale for $\mathrm{H} 4$, large public rewards can attenuate the negative effects; compared with small ones, large referral rewards increase referral likelihood, though this likelihood still is higher in the no-reward condition than in the large reward condition. Thus, it appears difficult for firms to increase referral likelihood when customers are already motivated to recommend an innovative offering. Our results also support the reinforcing effect of increasing reward sizes for less innovative services.

\section{Study 5: Moderating role of reward scheme}

In Study 5, we test another managerially relevant moderator of the detrimental effect of public referral rewards: varying reward schemes. Rewarding both recommenders and referral recipients (vs. only the recommender) may attenuate the detrimental effect of public referral rewards.

\section{Moderating role of reward scheme}

Different types of rewards and reward schemes exert unique impacts, depending on the perceptions evoked (Dur et al. 2010). Some incentives do not undermine motivation or behavior, such as verbal rewards (Deci et al. 1999), while others have neutral or positive effects on behaviors (Lacetera et al. 2012). Such varying effects are due to individuals' perceptions of the rewards relative to their initial needs (Deci et al. 1999). If a reward conflicts with these needs, individuals may feel directed by external forces, decreasing motivation and behavior.

Thus, we propose that a reward allocation scheme affects recommenders' motivation to refer. In practice, most firms offer a reward only to the recommender, but some firms split it between the parties. We adopt Ryu and Feick's (2007) terminology describing "reward-me" (only recommender gets reward) and "reward-both" (both recommender and referral recipients get rewarded) schemes. Reward-me and reward- 
both schemes differ conceptually in the economic benefits received, such that the former assigns the recommender the full economic benefit of the recommendation, but the latter grants referral recipients part of the reward (usually 50\%). These schemes also differ relative to the degree to which they affirm people's initial needs and goals and thus their relative contributions to a recommender's self-enhancement goals. Thus, with a public reward-me scheme, recommenders may perceive themselves as self-interested and driven by economic benefits, reducing internal satisfaction and positive selfesteem (Andreoni 1990), conflicting with motivations to self-enhance with the referral. Thus, public referral rewards in a reward-me scheme may not encourage referrals.

In contrast, in public reward-both schemes, the referral recipient receives some of the reward, so recommenders feel they are helping the recipient make a good decision and obtain money. Ryu and Feick (2007) show that rewarding both parties reduces the perceived social costs of a recommendation. Public reward-both schemes (vs. public reward-me schemes) thus offer recommenders room to view their referral behavior as compatible with their self-enhancement needs, reducing their negative effect.

H5a: With a reward-both (vs. reward-me) scheme, the negative effect of public referral rewards on referral likelihood for more innovative products and services is attenuated.

H5b: With a reward-both (vs. reward-me) scheme, the negative effect of public referral rewards on the indirect effect of innovativeness through expected selfenhancement on referral likelihood is attenuated.

\section{Participants, design, and procedure}

We use a 3 (referral reward scheme: no reward vs. rewardme vs. reward-both) $\times 2$ (product innovativeness: less vs. more) between-subjects design. A total of 337 participants (51\% women, $M_{\text {age }}=26.18$ years) were recruited for this study and randomly assigned to the conditions, using the same approaches and incentives as in Study 4. Research assistants approached potential participants over a twoweek period. In total, $64.3 \%$ of the people who verbally agreed to participate actually completed the online study. We employed the product scenario from Study 3, with the same fictitious brand (Smart Trolley) and innovativeness manipulation, but we added a reward scheme manipulation. The firm again reportedly informed participants via email that it had launched a CRP. In the reward-me condition, participants read only that the recommender would receive a referral reward of $€ 30(\sim \$ 36 ; 15 \%$ of the product price), while the reward-both condition indicated that both parties would receive $€ 15$ ( $\$ 18)$ each. In both cases, the recipient needed to provide the recommender's name and email address when purchasing the suitcase. We did not include this information in the no-reward condition.

\section{Measures}

We used the measures from Study 4. For the check of the reward scheme manipulation, we asked participants to indicate who received the referral reward (only recommender or both recommender and referral recipient). Two realism checks (Darley and Lim 1993) confirmed the realism of our experimental setting $(M=5.02, S D=1.38)$.

\section{Results}

Manipulation checks The manipulation of product innovativeness was successful. However, three participants failed the check of the implemented reward scheme and were excluded, leaving a final sample of 334 participants (see Web Appendix E for detailed manipulation checks).

Hypotheses tests We conducted a moderated mediation analysis (Hayes 2013; Model 8; bootstrapped with 5000 draws), with innovativeness ( $0=$ less innovative; $1=$ more innovative) as the independent variable, referral reward $(0=$ no reward; $1=$ reward me; $2=$ reward both $)$ as moderator, expected self-enhancement as mediator, referral likelihood as the dependent variable, and product involvement and CRP proneness as covariates. We created two dummy variables: Dummy 1 contrasts the reward-me and noreward conditions, and Dummy 2 compares the rewardboth and no-reward conditions (the reference category). Results appear in Table 8.

Innovativeness exerts a positive direct effect on referral likelihood when no reward is offered $(b=10.42, S E=4.09$, $p<.05,95 \% \mathrm{CI}=[2.37,18.47])$ and a negative direct effect when the reward is offered only to the recommender $(b=$ $-25.19, S E=3.27, p<.001,95 \% \mathrm{CI}=[-31.62,-18.76])$. In support of $\mathrm{H} 5 \mathrm{a}$, we find a positive direct effect of innovativeness on referral likelihood when the reward is provided to both the recommender and the referral recipient $(b=9.14$, $S E=3.54, p<.05,95 \% \mathrm{CI}=[2.17,16.11])$. For more innovative products, rewarding both the recommender and the recipient even increases referral likelihood compared with the no-reward condition $\left(M_{\text {noreward }}=78.60 ; M_{\text {rewardboth }}=\right.$ $87.17 ; t(108)=-3.22, p<.01)$, but rewarding only the recommender decreases this likelihood relative to the no-reward condition $\left(M_{\text {noreward }}=78.60 ; M_{\text {rewardme }}=47.73 ; t(90.57)=\right.$ 7.37, $p<.001$; see Figure W5 in Web Appendix C). Referral likelihood also is higher in the reward-both condition than in the reward-me condition $\left(M_{\text {rewardboth }}=87.17\right.$; $\left.M_{\text {rewardme }}=47.73 ; t(76.02)=-10.13, p<.001\right)$. The negative effect of public referral rewards thus is attenuated in the 
Table 8 Moderated mediation results, Study 5

Consequences

\begin{tabular}{|c|c|c|c|c|c|c|c|c|}
\hline \multirow[b]{2}{*}{ Antecedents } & \multicolumn{4}{|c|}{ Expected self-enhancement (ES) } & \multicolumn{4}{|c|}{ Referral likelihood (RL) } \\
\hline & Coefficient & $S E$ & $p$ & $95 \% \mathrm{CI}$ & Coefficient & $S E$ & $p$ & $95 \% \mathrm{CI}$ \\
\hline Product innovativeness (PI) & 1.81 & .18 & $<.001$ & {$[1.45,2.17]$} & 10.42 & 4.09 & $<.05$ & {$[2.37,18.47]$} \\
\hline Expected self-enhancement (ES) & - & - & - & - & 6.39 & 1.09 & $<.001$ & {$[4.26,8.53]$} \\
\hline \multicolumn{9}{|l|}{ Public referral reward } \\
\hline Dummy 1 (reward-me vs. no reward) & -.04 & .17 & $>.05$ & {$[-.38, .31]$} & 15.48 & 3.42 & $<.001$ & {$[8.75,22.21]$} \\
\hline Dummy 2 (reward-both vs. no reward) & .37 & .18 & $<.05$ & {$[.02, .72]$} & 9.77 & 3.51 & $<.01$ & {$[2.87,16.67]$} \\
\hline \multicolumn{9}{|l|}{ PI $\times$ Referral reward } \\
\hline PI $\times$ Dummy 1 & -1.54 & .25 & $<.001$ & {$[-2.03,-1.05]$} & -35.61 & 5.15 & $<.001$ & {$[-45.74,-25.49]$} \\
\hline PI $\times$ Dummy 2 & -.45 & .25 & $=.07$ & {$[-.94, .03]$} & -1.28 & 4.85 & $>.05$ & {$[-10.83,8.27]$} \\
\hline Product involvement & .10 & .04 & $<.01$ & {$[.03, .17]$} & 1.18 & .73 & $>.05$ & {$[-.25,2.62]$} \\
\hline \multirow[t]{3}{*}{ CRP proneness } & .08 & .04 & $<.05$ & {$[.01, .15]$} & .35 & .72 & $>.05$ & {$[-1.06,1.77]$} \\
\hline & \multicolumn{4}{|c|}{$\mathrm{R}^{2}=.46$} & \multirow{2}{*}{\multicolumn{4}{|c|}{$\begin{array}{l}\mathrm{R}^{2}=.42 \\
F(8,325)=29.46, p<.001\end{array}$}} \\
\hline & \multicolumn{4}{|c|}{ Conditional direct effects of PI at values of the reward } & & & & \\
\hline Public referral reward & Coefficient & Boot $S E$ & $p$ & $95 \% \mathrm{CI}$ & Coefficient & Boot $S E$ & $p$ & $95 \% \mathrm{CI}$ \\
\hline No reward & 1.81 & .18 & $<.001$ & {$[1.45,2.17]$} & 10.42 & 4.09 & $<.05$ & {$[2.37,18.47]$} \\
\hline Reward me & .27 & .17 & $>.05$ & {$[-.06, .59]$} & -25.19 & 3.27 & $<.001$ & {$[-31.62,-18.76]$} \\
\hline \multirow[t]{2}{*}{ Reward both } & 1.36 & .16 & $<.001$ & {$[1.04,1.68]$} & 9.14 & 3.54 & $<.05$ & {$[2.17,16.11]$} \\
\hline & \multicolumn{8}{|c|}{ Conditional indirect effects of PI via ES on RL at values of the reward } \\
\hline $\begin{array}{l}\text { Public referral reward } \\
\text { No reward }\end{array}$ & $\begin{array}{l}\text { Coefficient } \\
11.58\end{array}$ & $\begin{array}{l}\text { Boot } S E \\
2.48\end{array}$ & $\begin{array}{l}95 \% \text { CI } \\
{[6.95,16.69]}\end{array}$ & & & & & \\
\hline Reward me & 1.74 & 1.17 & {$[-.48,4.16]$} & & & & & \\
\hline Reward both & 8.69 & 1.93 & {$[5.25,12.87]$} & & & & & \\
\hline \multicolumn{9}{|l|}{ Index of moderated mediation } \\
\hline Dummy 1 (reward-me vs. no reward) & -9.84 & 2.45 & {$[-15.16,-5.52]$} & & & & & \\
\hline Dummy 2 (reward-both vs. no reward) & -2.88 & 1.67 & {$[-6.47, .10]$} & & & & & \\
\hline
\end{tabular}

Coefficient $=$ unstandardized regression coefficients; Dummy 1 contrasts the reward-me and no-reward conditions; Dummy 2 compares the reward-both and no-reward conditions

reward-both condition, in support of $\mathrm{H} 5 \mathrm{a}$. In the less innovative condition, the mean contrasts reveal differences between the no-reward and reward-me conditions $\left(M_{\text {noreward }}=55.31\right.$; $\left.M_{\text {rewardme }}=71.72 ; t(85.34)=-4.76, p<.001\right)$ and between the no-reward and reward-both conditions $\left(M_{\text {noreward }}=\right.$ $\left.55.31 ; M_{\text {rewardboth }}=69.39 ; t(105)=-3.70, p<.001\right)$. The difference between the reward-me and reward-both conditions is not significant $\left(M_{\text {rewardme }}=71.72 ; M_{\text {rewardboth }}=69.39\right.$; $t(118)=.74, p>.05)$.

To test H5b, we examine the conditional indirect effects of innovativeness through expected self-enhancement on referral likelihood, contingent on the public reward (no reward vs. reward-me vs. reward-both). The indices of the moderated mediation refer to the differences between the conditional indirect effects. The indirect effect in the reward-me condition decreases relative to the no-reward condition $(b=-9.84, S E=2.45,95 \% \mathrm{CI}=[-15.16$, $-5.52]$ ), but in the reward-both condition, the indirect effect is not different from that in the no-reward condition $(b=-2.88, S E=1.67,95 \% \mathrm{CI}=[-6.47, .10])$. As we suggest in $\mathrm{H} 5 \mathrm{~b}$, expected self-enhancement mediates the effect of innovativeness on referral likelihood in the no-reward $(b=11.58, S E=2.48,95 \% \mathrm{CI}=[6.95,16.69])$ and rewardboth $(b=8.69, S E=1.93,95 \% \mathrm{CI}=[5.25,12.87])$ conditions but not in the reward-me condition $(b=1.74, S E=$ $1.17,95 \% \mathrm{CI}=[-.48,4.16])$. The results reveal partial mediation, because the direct effect of innovativeness on referral likelihood is significant in the no-reward $(b=10.42$, $S E=4.09, p<.05,95 \% \mathrm{CI}=[2.37,18.47])$ and rewardboth $(b=9.14, S E=3.54, p<.05,95 \% \mathrm{CI}=[2.17,16.11])$ conditions.

\section{Discussion}

Study 5 reveals an important and managerially relevant boundary condition. The detrimental effect of public referral 
rewards on referral likelihood for more innovative offerings is mitigated by rewarding both parties. Rewarding both parties offers participants more room to align their incentivized referral behavior with their self-enhancement needs (e.g., being helpful and generous), resulting in increased referral likelihood. However, we find no difference between rewarding only the recommender and rewarding both for less innovative products.

\section{Conclusion and implications}

Although CRPs are widely viewed as effective relationship tools that can facilitate referral behavior and increase customer bases (Ryu and Feick 2007), our research qualifies these findings by showing that public referral rewards effectively boost customer acquisition only for less innovative offerings. For more innovative offerings, customers exhibit a high natural, unrewarded referral likelihood, and offering a public referral reward decreases this likelihood. With one field study and four experiments, we examine this negative effect and identify managerially relevant boundary conditions, related to the reward's visibility, size, and scheme.

\section{Theoretical implications}

Finding ways to increase the customer base for more innovative offerings constitutes a central marketing challenge (Peres et al. 2010). Prior research highlights the importance of customer referrals but also notes the high costs of firm-initiated strategies to encourage them (e.g., Lee and O'Connor 2003). We also show that marketing programs aimed at stimulating customers' recommendations through referral rewards can backfire and hinder innovation success; in particular, rewards can interfere with referral behavior, which is key for new product diffusion. With this study, we demonstrate that public CRPs for more innovative offerings can reduce referral behavior.

While prior research indicates that CRPs perform better than other promotional tools (e.g., Kornish and Li 2010), we illustrate the differential effects of public referral rewards, including their unintended, potentially negative effects. In particular, CRP effectiveness depends on the type of offering, with rewards for less innovative offerings increasing referral likelihood which is not true for more innovative offerings.

In addition to identifying the types of offerings, we uncover several boundary conditions. Specifically, the detrimental effect depends on reward visibility, such that private referral rewards enable recommenders to achieve self-enhancement while also attenuating the negative effect of the reward on referral likelihood. Increasing the referral reward size also attenuates the negative effects of public referral rewards for more innovative offerings and increases referral likelihood for less innovative offerings. Implementing a public reward-both scheme (vs. a public reward-me scheme) allows recommenders room to interpret their behavior compatibly with their selfenhancement needs, reducing rewards' detrimental effects. Rewarding both parties increases recommenders' referral likelihood for more innovative offerings, compared with both the no-reward and reward-me conditions. However, we find no difference between rewarding only the recommender and rewarding both for less innovative offerings.

The results also indicate the importance of recognizing that motivations to self-enhance and financial rewards interact to influence referral likelihood for more innovative offerings. We find that extrinsic stimuli, such as referral rewards, can undermine motivational states, such as need to self-enhance. We also rule out several alternative explanations for these detrimental effects, including intention to help or perceived social costs. By presenting a detailed analysis of the underlying process producing this negative effect of rewards on referral behavior, we advance research on the potential negative effects of incentives overall (Ariely et al. 2009).

\section{Managerial implications}

Managers who are considering whether to implement CRPs can rely on several insights from our research. First, they should recognize that a base level of referral potential already exists for more innovative offerings. Customers like to recommend such offerings to others, because it serves their psychological self-interest. Attempts to harness customer advocacy through financial rewards appear to erode, rather than increase, their willingness to refer these more innovative products and services, which represents a note of caution for managers. Customer referrals might be a critical success factor for innovative launches (Kawakami and Parry 2013), but contrary to the expectations and insights for less innovative offerings, public referral rewards for more innovative offerings can impede their diffusion. Managers must take care when implementing public CRPs, especially financial ones, for more innovative offerings. This is not to suggest that firms should avoid public CRPs completely; they are effective for less innovative offerings. Rather, managers introducing highly novel offerings might consider devoting fewer marketing resources to CRPs and target new customers in other ways.

Second, if firms decide to offer public financial rewards, they should offer larger incentives rather than smaller ones. Study 4 results suggest public rewards that match the purchase price of the innovative offering can mitigate the detrimental 
effects on referral behavior. Regardless of innovativeness levels, managers should study the curve progression between reward size and referral likelihood to determine an optimal reward size. For example, if the curve exhibits a concave function, managers can anticipate decreasing returns on their investments when offering greater financial rewards. However, offering no rewards and relying on customers' natural drive to recommend more innovative offerings appears promising as an acquisition strategy.

Third, whether reward schemes benefit both parties constitutes an important and managerially relevant boundary condition. Managers who seek new customers for their more innovative offerings should consider offering financial rewards to both parties in the dyad, thereby increasing the likelihood of a referral (Study 5). Notably though, we find no difference in referral likelihood across these schemes for less innovative offerings.

Fourth, we show that marketing managers can avoid some detrimental effects of referral rewards for innovative offerings by not disclosing the reward to recipients. However, we caution against this approach, because of ethical concerns about the practice. Combining these insights, managers can better predict when referral rewards are more likely to exert negative effects, as well as when and how they might positively influence customer behavior.

\section{Limitations and further research}

Our research focuses solely on recommenders and their referral likelihood. For CRPs to be effective, a high referral likelihood on the recommender side must combine with the referral recipient's receptivity to the recommendation. Examining referral recipients' perceptions of and reactions to rewards was beyond the scope of the current research; further research might examine this question at the dyad level. For example, financial rewards for referrals might affect perceived trustworthiness of the recommendation for more innovative offerings, thus influencing referral recipients' intentions to adopt the recommended offering.

The use of fictitious brands here did not allow us to study the potential influence of brand strength on referral behavior. With Ryu and Feick (2007) finding that strong brands offer higher quality and value than weak brands, addressing brand strength into this topic would be useful.

Finally, other types of rewards (e.g., non-monetary incentives) might not undermine referral motivation as much as financial rewards (Heymann and Ariely 2004). However, we know of no research that investigates the effects of non-monetary referral rewards on referral behavior for more innovative offerings. Firms offer a wide range of referral reward types, such as in-kind rewards and redeemable points, suggesting a need for further research into this topic.

\section{Appendix}

\section{Scale items and measurement properties}

Perceived innovativeness (adapted from Stock 2011). (Cronbach's $\alpha=.87$ [Study 1]; .87 [Pretest Study 2]; .89 [Study 2]; .82 [Pretest Study 3]; .93 [Study 3]; .90 [Study 4]; .88 [Study 5])

- I think the [product/service] is innovative compared to other [products/services].

- The [product/service] differs from competing [products/ services] in the market.

- The [product/service] can be characterized as being very new to the market.

Expected satisfaction of the need for self-enhancement (adapted from Alexandrov et al. 2013)

(Cronbach's $\alpha=.95$ [Study 1]; .71 [Pretest Study 2]; .92 [Study 2]; .90 [Pretest Study 3]; .93 [Study 3]; .80 [Study 4]; .80 [Study 5])

If I recommend this [product/service] in a conversation...

- It will create the impression that I am an interesting person.

- I will receive positive feedback from others.

- I will create a positive impression on others.

Intention to help others (adapted from Alexandrov et al. 2013) (Cronbach's $\alpha=.86$ [Study 2])

- When I recommend [firm] I help the referral recipient to be a better customer.

- I help the referral recipient to get the information she/he needs, when I recommend [firm].

- When I recommend [firm] I help the referral recipient to form an opinion about the brand.

Perceived social costs (adapted from Jin and Huang 2014). (Cronbach's $\alpha=.87$ [Study 2])

- The referral recipient will think that you are betraying him/ her for your own benefit.

- You will become more estranged from the referral recipient after the recommendation.

- The referral recipient will think that you are helping him/ her. (R)

- The referral recipient will feel uncomfortable when I recommend [firm].

- The referral recipient will think that he/ she is being taken advantage of by you.

Product involvement (adapted from Beatty and Talpade 1994). 
(Cronbach's $\alpha=.74$ [Study 1]; .78 [Study 2]; .74 [Study 3]; .90 [Study 4]; .87 [Study 5])

- In general I have a strong interest in [product category].

- [Product category] is very important to me.

- [Product category] matters a lot to me.

- I get bored when other people talk to me about [product category]. (R)

Product satisfaction (adapted from De Wulf et al. 2001)

(Cronbach's $\alpha=.96$ [Study 1])

- I am satisfied with the product I last purchased at [name of the online shop].

- Overall, I am happy with the product I last purchased at [name of the online shop].

- Overall, my experiences with the product I last purchased at [name of the online shop] are good.

CRP (= customer referral reward program) proneness (adapted from Lichtenstein et al. 1990)

(Cronbach's $\alpha=.93$ [Study 2]; .93 [Study 3]; .82 [Study 4]; .81 [Study 5])

With a statement as to what CRPs are, the following statements followed:

- Participating in CRPs makes me feel good.

- Beyond the referral reward I get, participating in CPRs gives me a sense of joy.

- I enjoy participating in CRPs.

Perceived reward size (adapted from Ryu and Feick 2007). (Cronbach's $\alpha=.89$ [Study 4])

- I think the referral reward is very attractive.

- I think the referral reward offered by [firm] is large.

Realism check (adapted from Darley and Lim 1993). (Cronbach's $\alpha=.88$ [Study 2]; $=.89$ [Study 3]; = .84 [Study 4]; $=.82$ [Study 5])

- I could imagine a situation like this happening to me in real life.

- I believe the situation was very realistic.

Referral likelihood (adapted from Ryu and Feick 2007).

Measured on a 100 -point scale: $0 \%=$ certain not to recommend the [product/service], $100 \%=$ certain to recommend the [product/service].

Open Access This article is distributed under the terms of the Creative Commons Attribution 4.0 International License (http:// creativecommons.org/licenses/by/4.0/), which permits unrestricted use, distribution, and reproduction in any medium, provided you give appropriate credit to the original author(s) and the source, provide a link to the Creative Commons license, and indicate if changes were made.

Publisher's note Springer Nature remains neutral with regard to jurisdictional claims in published maps and institutional affiliations.

\section{References}

Alchian, A. A., \& Demsetz, H. (1972). Production, information costs and economic organization. American Economic Review, 62(5), 777795.

Alexandrov, A., Lilly, B., \& Babakus, E. (2013). The effects of socialand self-motives on the intentions to share positive and negative word of mouth. Journal of the Academy of Marketing Science, 41(5), 531-546.

Anderson, E. W. (1998). Customer satisfaction and word of mouth. Journal of Service Research, 1(1), 5-17.

Andreoni, J. (1990). Impure altruism and donations to public goods: A theory of warm-glow giving. The Economic Journal, 100(401), 464- 477.

Aral, S. (2011). Identifying social influence: A comment on opinion leadership and social contagion in new product diffusion. Marketing Science, 30(2), 217-223.

Ariely, D., Bracha, A., \& Meier, S. (2009). Doing good or doing well? Image motivation and monetary incentives in behaving prosocially. American Economic Review, 99(1), 544-555.

Ashraf, N., Bandiera, O., \& Jack, B. K. (2014). No margin, no mission? A field experiment on incentives for public service delivery. Jorurnal of Public Economics, 120, 1-17.

Bagozzi, R. P., \& Yi, Y. (2012). Specification, evaluation, and interpretation of structural equation models. Journal of the Academy of Marketing Science, 40(1), 8-34.

Bansal, H. S., \& Voyer, P. A. (2000). Word-of-mouth processes within a services purchase decision context. Journal of Service Research, 3(2), 166-177.

Bass, F. M. (1969). A new product growth model for consumer durables. Management Science, 15(1), 215-227.

Beatty, S. E., \& Talpade, S. (1994). Adolescent influence in family decision making: A replication with extension. Journal of Consumer Research, 21(2), 332-341.

Bénabou, R., \& Tirole, J. (2006). Incentives and prosocial behavior. American Economic Review, 96(5), 1652-1678.

Berger, J. (2014). Word-of-mouth and interpersonal communication: A review and directions for future research. Journal of Consumer Psychology, 24(4), 586-607.

Bluesmart Referral Program (2017). Bluesmart - Get rewarded and make your friends love you! (available at http://bluesmart.referralcandy. com/). Accessed 6 Feb 2017.

Brown, J. D., Collins, R. L., \& Schmidt, G. W. (1988). Self-esteem and direct versus indirect forms of self-enhancement. Journal of Personality and Social Psychology, 55(3), 445-453.

Brown, T. J., Barry, T. E., Dacin, P. A., \& Gunst, R. F. (2005). Spreading the word: Investigating antecedents of consumers' positive word-ofmouth intentions and behaviors in a retailing context. Journal of the Academy of Marketing Science, 33(2), 123-138.

Castellion, G., \& Markham, S. K. (2013). Perspective: New product failure rates: Influence of argumentum ad populum and self-interest. Journal of Product Innovation Management, 30(5), 976-979.

Darley, W. K., \& Lim, J.-S. (1993). Store choice behavior for pre-owned merchandise. Journal of Business Research, 27(1), 17-31.

De Angelis, M., Bonezzi, A., Peluso, A. M., Rucker, D. D., \& Costabile, M. (2012). On braggarts and gossips: A self-enhancement account 
of word-of-mouth generation and transmission. Journal of Marketing Research, 49(4), 551-563.

de Matos, C. A., \& Rossi, C. A. V. (2008). Word-of-mouth communications in marketing: A meta-analytical review of the antecedents and moderators. Journal of the Academy of Marketing Science, 36(4), 578-596.

De Wulf, K., Odekerken, G., \& Iacobucci, D. (2001). Investments in consumer relationships: A cross-country and cross-industry exploration. Journal of Marketing, 65(4), 33-50.

Deci, E. L., Koestner, R., \& Ryan, R. M. (1999). A meta-analytic review of experiments examining the effects of extrinsic rewards on intrinsic motivation. Psychological Bulletin, 125(6), 627-668.

Dichter, E. (1966). How word-of-mouth advertising works. Harvard Business Review, 44(6), 147-166.

Douglas, S. P., \& Craig, C. S. (2007). Collaborative and iterative translation: An alternative approach to back translation. Journal of International Marketing, 15(1), 30-43.

Dubé, J.-P., Luo, X., \& Fang, Z. (2017). Self-signaling and prosocial behavior: A cause marketing experiment. Marketing Science, 36(2), 161-186.

Dur, R., Non, A., \& Roelfsema, H. (2010). Reciprocity and incentive pay in the workplace. Journal of Economic Psychology, 31(4), 676-686.

East, R., Hammond, K., \& Lomax, W. (2008). Measuring the impact of positive and negative word of mouth on brand purchase probability. International Journal of Research in Marketing, 25(3), 215-224.

Frey, B. S., \& Oberholzer-Gee, F. (1997). The cost of price incentives: An empirical analysis of motivation crowding- out. American Economic Review, 4(4), 746-755.

Garcia, R., \& Calantone, R. (2002). A critical look at technological innovation typology and innovativeness terminology: A literature review. Journal of Product Innovation Management, 19(2), 110-132.

Garnefeld, I., Eggert, A., Helm, S. V., \& Tax, S. S. (2013). Growing existing customers' revenue streams through customer referral programs. Journal of Marketing, 77(4), 17-32.

Gneezy, U. (2005). The W effect of incentives. Discussion paper, University of Chicago.

Gneezy, U., \& Rustichini, A. (2000). Pay enough or don't pay at all. The Quarterly Journal of Economics, 115(3), 791-810.

Hayes, A. F. (2013). Introduction to mediation, moderation, and conditional process analysis: A regression-based approach. New York: Guilford Publications.

Heymann, J., \& Ariely, D. (2004). Effort for payment. A tale of two markets. Psychological Science, 15(11), 787-793.

Hulland, J., Baumgartner, H., \& Smith, K. M. (2018). Marketing survey research best practices: Evidence and recommendations from a review of JAMS articles. Journal of the Academy of Marketing Science, 46(1), 92-108.

Jin, L., \& Huang, Y. (2014). When giving money does not work: The differential effects of monetary versus in-kind rewards in referral reward programs. International Journal of Research in Marketing, 31(1), 107-116.

Katila, R., \& Ahuja, G. (2002). Something old, something new: A longitudinal study of search behavior and new product introduction. Academy of Management Journal, 45(6), 1183-1194.

Kawakami, T., \& Parry, M. E. (2013). The impact of word of mouth sources on the perceived usefulness of an innovation. Journal of Product Innovation Management, 30(6), 1112-1127.

Kornish, L. J., \& Li, Q. (2010). Optimal referral bonuses with asymmetric information: Firm-offered and interpersonal incentives. Marketing Science, 29(1), 108-121.

Lacetera, N., Macis, M., \& Slonim, R. (2012). Will there be blood? Incentives and displacement effects in pro-social behavior. American Economic Journal: Economic Policy, 4(1), 186-223.

Lee, Y., \& O'Connor, G. C. (2003). The impact of communication strategy on launching new products: The moderating role of product innovativeness. Journal of Product Innovation Management, 20(1), 4-21.
Lichtenstein, D. R., Netemeyer, R. G., \& Burton, S. (1990). Distinguishing coupon proneness from value consciousness: An acquisition-transaction utility theory perspective. Journal of Marketing, 54(3), 54-67.

López-López, I., Ruiz-de-Maya, S., \& Warlop, L. (2014). When sharing consumption emotions with strangers is more satisfying than sharing them with friends. Journal of Service Research, 17(4), 475-488.

Mittal, B. (1995). Comparative analysis of four scales of consumer involvement. Psychology and Marketing, 12(7), 663-682.

Murray, K. B., \& Schlacter, J. L. (1990). The impact of services versus goods on consumers' assessment of perceived risk and variability. Journal of the Academy of Marketing Science, 18(1), 51-65.

Nidumolu, R., Prahalad, C. K., \& Rangaswami, M. R. (2009). Why sustainability is now the key driver of innovation. Harvard Business Review, 87(9), 57-64.

Orsingher, C., \& Wirtz, J. (2018). Psychological drivers of referral reward program effectiveness. Journal of Services Marketing, 32(3), 256-268.

Peres, R., Muller, E., \& Mahajan, V. (2010). Innovation diffusion and new product growth models: A critical review and research directions. International Journal of Research in Marketing, 27(2), 91-106.

Prendergast, C. (1999). The provision of incentives in firms. Journal of Economic Literature, 37(1), 7-63.

Rosen, E. (2009). The anatomy of buzz revisited: Real-life lessons in word-of-mouth marketing. New York: Doubleday.

Ryu, G., \& Feick, L. (2007). A penny for your thoughts: Referral reward programs and referral likelihood. Journal of Marketing, 71(1), 84-94.

Schmitt, P., Skiera, B., \& Van den Bulte, C. (2011). Referral programs and customer value. Journal of Marketing, 75(1), 46-59.

Sedikides, C. (1993). Assessment, enhancement, and verification determinants of the self-evaluation process. Journal of Personality and Social Psychology, 65(2), 317-338.

Sedikides, C., \& Gregg, A. P. (2008). Self-enhancement: Food for thought. Perspectives on Psychological Science, 3(2), 102-116.

Steinhoff, L., \& Palmatier, R. (2016). Understanding loyalty program effectiveness: Managing target and bystander effects. Journal of the Academy of Marketing Science, 44(1), 88-107.

Stock, M. R. (2011). How does product program innovativeness affect customer satisfaction? A comparison of goods and services. Journal of the Academy of Marketing Science, 39(6), 813-827.

Stumpf, C., \& Baum, M. (2016). Customer referral reward-brand-fit: A schema congruity perspective. Psychology and Marketing, 33(7), 542-558.

Sundaram, D. S., Mitra, K., \& Webster, C. (1998). Word-of-mouth communications: A motivational analysis. Advances in Consumer Research, 25, 527-531.

Swann, W. B., Jr., Pelham, B. W., \& Krull, D. S. (1989). Agreeable fancy or disagreeable truth? Reconciling self-enhancement and self-verification. Journal of Personality and Social Psychology, 57(5), 782-791.

Teichmann, K., Stokburger-Sauer, N. E., Plank, A., \& Strobl, A. (2015). Motivational drivers of content contribution to company-versus consumer-hosted online communities. Psychology and Marketing, 32(3), 341-355.

Truong, Y., Klink, R. R., Simmons, G., Grinstein, A., \& Palmer, M. (2017). Branding strategies for high-technology products: The effects of consumer and product innovativeness. Journal of Business Research, 70, 85-91.

Wirtz, J. S., \& Chew, P. (2002). The effects of incentives, deal proneness, satisfaction and tie strength on word-of-mouth behavior. International Journal of Service Industry Management, 13(2), 141-162.

Wirtz, J., Orsingher, C., Chew, P., \& Tambyah, S. K. (2013). The role of metaperception on the effectiveness of referral reward programs. Journal of Service Research, 16(1), 82-98.

Wirtz, J., Tang, C. S., \& Georgi, D. (2018). Successful referral behavior in referral reward programs. Journal of Service Management, in press.

Wojnicki, A. C., \& Godes, D. (2008). Word-of-mouth as self-enhancement. Harvard Business School, Marketing Research Paper, No. 06-01. 